Vol. 4, n² | 2000

Varia

\title{
Atténuer le mal de l'infamie : le réformisme conservateur de Pierre-François Muyart de Vouglans
}

Michel Porret

\author{
(2) OpenEdition \\ Journals \\ Édition électronique \\ URL : https://journals.openedition.org/chs/828 \\ DOI : $10.4000 /$ chs.828 \\ ISSN : 1663-4837 \\ Éditeur \\ Librairie Droz \\ Édition imprimée \\ Date de publication : 1 juin 2000 \\ Pagination : $95-120$ \\ ISBN : 2-600-00477-7 \\ ISSN : 1422-0857
}

Référence électronique

Michel Porret, "Atténuer le mal de l'infamie : le réformisme conservateur de Pierre-François Muyart de Vouglans ", Crime, Histoire \& Sociétés / Crime, History \& Societies [En ligne], Vol. 4, n² I 2000, mis en ligne le 02 avril 2009, consulté le 22 mars 2022. URL : http://journals.openedition.org/chs/828 ; DOI : https://doi.org/10.4000/chs.828 


\title{
Atténuer le mal de l'infamie: le réformisme conservateur de Pierre-François Muyart de Vouglans
}

\author{
Michel Porret'
}

Le noble perd l'honneur et réponse en cour, pendant que le vilain, qui n'a point d'honneur, est puni en son corps. Montesquieu, De l'Esprit des lois, Genève, $1748, \mathrm{VI}, \mathrm{x}$.

Je crois pouvoir d'autant moins me dispenser de requérir contre Lapierre une peine corporelle et infamante, que les vols de ce genre deviennent très fréquents. Si l'on pouvait présumer que l'accusé, séduit par l'occasion ou par le besoin, n'est pas destiné par état à ce malheureux métier [de voleur], on pourrait en retrancher l'infamie. Elle a le grand inconvénient de ne laisser presque au coupable pour subsister que la ressource d'un nouveau crime. «Réquisitoire» du Procureur Général Jean-Robert Tronchin contre un ouvrier incriminé pour «vol domestique», Genève, 1766.

\section{LA NOTE D'INFAMIE}

T ' infamie, selon Beccaria, est un signe de la réprobation publique, qui prive le

coupable de la considération générale, de la confiance de sa patrie et de cette sorte de fraternité qui lie les membres de la société »². Durant l'Ancien Régime, mise en scène publiquement dans une finalité d'intimidation générale par l'exécuteur de la haute-justice ${ }^{3}$, l'infamie pénale flétrissait la «réputation, l'honneur et la probité » đe l'homo criminalis. Agissant selon une «morale universelle», les juges ordonnaient ainsi sa flétrissure juridique pour signaler à la société combien son immoralité culminait dans l'《atrocité» de son crime 4 . Imprescriptible, donnant sens à la condamnation morale, la «note d'infamie» posthume flétrissait en outre le cadavre d'un

1 Corédacteur des Annales Jean-Jacques Rousseau ainsi que d'Équinoxe. Revue de sciences humaines, travaille sur le républicanisme, la culture juridique et pénale des Lumières, les pratiques médico-légales jusqu'à la fin du XIX ${ }^{e}$ siècle, ainsi que le contrôle judiciaire de l'imprimerie avant 1800 , objets auxquels il a consacré près de 80 publications; vient de publier l'édition critique de Montesquieu, Réflexions sur la monarchie universelle en Europe, Gendve, Droz, 1999.

4 Art. «infamie», Encyclopédie méthodique, Jurisprudence (1785 V, pp. 162-163). 
condamné (suicidés, duellistes) traîné sur la «claie d'infamie» à travers la cité, puis abandonné en un lieu immonde (voirie), voire exposé à la potences.

Intolérable pour l'homme libre, l'infamie naît avec la cité grecque, où, à côté du bannissement des citoyens frappés d'atimie, elle s'exécute dramatiquement: entrave corporelle du condamné (membres, cou), emprisonnement prolongé, nudité exhibée sur une pierre au milieu de l'Agora, lynchage, voire, en cas d'adultère, humiliation publique par une possession rectale, symbolisée par l'intromission d'un raifort dans les fondements du coupable dont le corps a été rasé pour en effacer toute identité sexuelle. «Mort, prison, fustigation, exposition publique ignominieuse, aussi bien sur un escabeau que debout, relégation vers les sanctuaires éloignés»: selon Platon, préventives, les lois de la République ajouteront à la neutralisation du «coupable» sa flétrissure morale et physique afin de le priver de ses droits civiques. Remèdes du crime, les lois pénales des Grecs, autorisant de torturer un esclave pour prouver le délit par l'aveu, permettent de défigurer celui qui les transgresse: marqué du feu ardent ou de la chouette d'infamie, son visage exprime la honte du paria ${ }^{6}$. Au rituel de la stigmatisation corporelle et morale s'ajoute celui de l'amende honorable: la «promenade infamante» du condamné, le cou enserré dans une gangue, le corps revêtu du chitôn d'infamie couleur safran?

Après les Grecs, les Romains recourent aussi à l'infamie: dès la République (509 av. J.-C.), le jus romanum permet la torture judiciaire et la flétrissure. La quaestio (tormenta), réservée d'abord aux esclaves, s'applique progressivement aux personnes de condition libre, ainsi qu'aux citoyens. Elle vise à la confessio, cette «reine des preuves», soit l'aveu de la culpabilité ${ }^{8}$. Brisant ainsi les corps, le droit romain inflige aussi la «note d'infamie» pour aggraver la peine d'un accusé «questionné ». À ce propos, les juristes romains désignent l'infamie de fait, née d' «actions infamantes» ou contraires à la morale dominante (prostitution, métier d'acteur de théâtre, prévarication) : ces transgressions peuvent entraîner le blâme officieux prononcé par un magistrat ou celui «naturel» de la part du pater familia. D'autre part, les juristes romains qualifient positivement l'infamie de droit. Cette dernière est provoquée par une décision de justice qui flétrit légalement le condamné incriminé pour adultère, vol, rapines ou injures. Les crimes capitaux, particulièrement «atroces» (incendie criminel ou vol commis avec violence), flétrissent d'infamie leurs auteurs poursuivis par jugement public puis exécutés'. Ainsi, selon le Digeste, l'individu qui désacralise de nuit ou de jour les sanctuaires par des dépradations intérieures ou extérieures «aura les yeux crevés [...], sera battu de verges, aura les cheveux coupés et sera banni $\gg^{10}$. L'infamie flétrit radicalement le corps du transgresseur pour signaler, avant son élimination, l'atrocité de son méfait.

5 Jousse (1771, I, pp. 113-114), «De l'Infamie».

6 Les Lois, IX, 853, 855; Page Du Bois (1991, pp. 47-62).

7 Aristote, La Politique, III, 1, 23 (atimie); Halm-Tisserant (1998, pp. 69-109).

8 Les cinquante livres du Digeste (1805, t. VII, 48, 18), «De Quæstionibus»; Fasano (1997), passim.

9 T. I: 3, 2, 1-25 pp. 190-199, «De Ceux qui sont notés d'infamie», ibid., (t. VII: 48, 1-23 pp. 302434), passim. Cf. Pommeray (1937). Le droit pénal romain suscite la réprobation des réformateurs hostiles aux peines corporelles et infamantes; par exemple, Essai sur la politique et la législation des Romains (traduit de l'italien, Pise, 1772) Paris, An III, présenté comme une «production du célèbre Beccaria» (p. vij), chap. XIV, «Des Lois criminelles», pp. 343-393. 
Si l'empereur Constantin (280/288-337), doctrinaire du christianisme comme religion d'État pour l'Empire romain, exige que l'inscriptio d'infamie (K, Kalumnia) ne soit appliquée qu'aux mains et non plus au visage, afin que la face de l'homme faite à l'image de Dieu échappe à la flétrissure, les pratiques médiévales de la stigmatisation et de la ségrégation, légitimées par les conciles, frappent alors les «infâmes», identifiés par des signes distinctifs: cagots, lépreux, Juifs, Sarazzins, hérétiques, prostituées, sorcières et bannis. La «roue jaune» du Juif, l'accoutrement terrorisant du lépreux (chapeau écarlate, costume noir ou gris, gants, cliquette bruyante), voire le manteau rayé ou l'«aiguillette rouge» des prostituées, signalent ces figures de la marginalité associées à la contagion mortifère du mal physicomoral ${ }^{11}$. Dramatisée par cette infamie signalétique, obligatoire sous peine de fouet, l'identification du réprouvé veut protéger la cité contre la contamination. Malade, pécheur ou criminel, l'individu flétri se signale à l'opprobre public: marque corporelle, tonsure, «costume de la honte», cavalcade ridicule sur un âne avec un chapeau de paille, «écriteau d'infamie» mentionnant le délit commis et la peine subie. Prolongeant la contrition et la «pénitence publique» du pécheur (idolâtrie, fornicatio, homicides), la «voie de l'infamie» menait, via l'amende honorable, à la «relégation solennelle» du bannissement, voire à l'agonie lente ou rapide sur le gibet ${ }^{12}$.

Marquée par l'héritage gréco-romain et chrétien de la flétrissure, renforcée dès le XVI ${ }^{\complement}$ siècle avec le monopole pénal de l'État, l'infamie dramatise le spectacle des rituels punitifs de l'Ancien Régime, comme le souligne en 1788 à Genève cette sentence exécutée en effigie contre un fugitif: « ledit Jacques C. [sera] lié et garrotté par l'Exécuteur de la Haute-Justice et conduit à la place de Plainpalais, pour là, autour du Gibet dressé à cet effet, être battu de verges, la hart au col, jusqu'à effusion de sang, à être banni à perpétuité de la ville et des terres sous peine de mort [...] pour servir d'exemple à quiconque semblable crime voudrait commettre ${ }^{13}$. Légalisant dans le royaume de France la procédure inquisitoire (écrite, secrète, basée sur l'aveu et l'enquête pour fonder la preuve des délits), l'Ordonnance criminelle de 1670 encadre l'arbitraire des juges et énonce sommairement l'éventail des neuf peines principales $(\mathrm{XXV}, 13)^{14}$. Infamantes, les «peines afflictives » stigmatisent le corps du condamné, entravent sa liberté: question ou torture, galère ou bannissement à temps. Les peines qui «rendent infâme»en détruisant l'honneur ou la réputation du condamné, sont donc, après la mort naturelle par pendaison: les galères perpétuelles, le bannissement perpétuel, le blâme, l'amende honorable, la mise au carcan, la fustigation jusqu'au sang, la marque avec la fleur de lys ou la lettre indiquant le crime commis ainsi que la récidive ( $V$ pour voleur; $V V$ ou $R$ pour voleur récidiviste; $G$ pour galérien).

\1 Burford, Shulman (1992, chap. 4, 5, 9); Ginzburg (1989, pp. 43-93; Goglin (1976, pp. 186-189); Quanter $(1901 ; 1891$, pp. 1-23, 66, 95, 114-115, 120-121, 146-174, 177, 183).

12 Galtier (1932, pp. 234-235, 256-264, 361-381); Zaremska (1996, pp. 173-187).

13 Archives d'État de Genève (AEG), Procès Criminel (PC) série I, 15351, 1788, « viol d'une jeune fille de quatre ans $»$.

14 En usage jusqu'au Code d'instruction criminelle du 17 novembre 1808 (cf. Tripier, 1850, pp. 681796), l'Ordonnance criminelle, Saint-Germain-en-Laye, août 1670 (28 titres; plusieurs éditions jusqu'en 1776), est publiée in Isambert (1821-1833, t. XVIII, pp. 372-423), ainsi que in Jeanclos (1996, pp. 22-43); dorénavant: O.C., 1670. Parmi les doctrinaires-patriciens de son temps, Daniel Jousse, élève de Pothier, Lieutenant de Police puis Conseiller honoraire au Châtelet d'Orléans, la commente dans son Nouveau commentaire sur l'Ordonnance criminelle du mois d'Août 1670, Paris, 1763, puis 1777 . 
Ajoutant à la sanction pénale le déshonneur de la flétrissure morale ou corporelle, la marque d'infamie constitue, en outre, une forme archaïque de casier judiciaire gravé au fer rouge sur le corps de l'homo criminalis ${ }^{15}$. À Genève, le Registre des signalements provenant de l'étranger (1774-1791) enregistre près de 300 Avis de recherches et Signalements (manuscrits ou imprimés) envoyés neuf fois sur dix par la Chancellerie de la République de Berne, mais concernant vingt suspects ou récidivistes sur cent venus de France. Mettant en lumière un réseau de coopération judiciaire organisé à travers l'ancienne confédération helvétique mais touchant l'Italie du Nord, la Savoie et la France, ce sommier archaïque, étendu aux détenus de Genève, établit des biographies individuelles et détaille les signes particuliers des hommes ou des femmes recherchés: voix grêle ou grave, taille, maigreur ou embonpoint, forme du visage, des mains et des pieds, calvitie, couleur des cheveux et des yeux, proéminence ou modestie nasale, profil des oreilles, particularités dermatologiques, cicatrices. Les Signalements de condamnés, prisonniers et suspects évoquent en outre leur marque d'infamie (une ou plusieurs) qui les signale comme des «scélérats endurcis dans le crime» (déserteurs, repris de justice, galériens) ${ }^{16}$.

Dans toute l'Europe de l'époque moderne, les rituels publics de la flétrissure incarnaient ainsi dans le corps du condamné, hué ou acclamé sur le gibet par la foule, le mal concret et symbolique de la peine mise en scène publiquement, par l'exécuteur de la haute-justice, comme un douloureux «spectacle de l'horreur» fait pour humilier le condamné, le rendre identifiable par la marque, intimider les adeptes du crime et proclamer le monopole pénal de l'État". "En Matière Criminelle, le point le plus difficile est l'imposition de la peine: c'est le but et la fin de la procédure, et le seul fruit qui revient au public [...], par l'exemple et la terreur quand elle est bien appliquée sur un coupable»: théâtralisant publiquement cette pédagogie de l'effroi que l'avocat au Parlement de Paris Antoine Bruneau inscrit dans la prévention générale des délits ${ }^{18}$, le protocole de l'infamie perdure jusqu'à l'aube du $\mathrm{XIX}^{\mathrm{e}}$ siècle. Avant la légalité des délits et des peines qu'assure le code pénal $(1791,1810)$, la flétrissure aggravait ainsi la sentence des condamnés prononcée en dernier ressort par une cour criminelle. Or, bien que couramment dénoncée dès les années 1750 par les magistrats éclairés et les réformateurs du droit criminel en raison de son effet désastreux sur la récidive et ses retombées déshonorantes sur la famille de l'accusé ${ }^{19}$, l'infamie pénale survit partiellement à l'ancien régime des crimes et des châtiments: "Quiconque aura été condamné à la peine des travaux forcés à perpétuité, sera flétri sur la place publique, par l'application d'une empreinte avec un fer brôlant sur l'épaule droite». Fondant l'État de droit, le code

15 Jouvenet (1900, pp. 21-38).

16 AEG, Jur Pén H2 (1); ainsi que Jur Pén H2 (2), Registre de signalements et de visites faites à Genève de condamnés, de prisonniers et de suspects (merci à Chantal Perroud, étudiante en histoire moderne, d'avoir dépouillé cette documentation encore non exploitée). Porret (1995, La biographie des scélérats ; 1998, «Signalement»).

17 Beattie (1986, pp. 450-490); Gatrell (1994, pp. 29-89); McLynn (1989, pp. 257-276); Masur (1989, pp. 25-49); Panico (1985); Puppi (1990, pp. 10-67); Spierenburg (1984, pp. 13-109).

18 Bruneau (1716, $\mathrm{II}^{\mathrm{e}}$ partie, p. [8]).

19 Beccaria, (1764, 1965, xxiii); Brissot De Warville (1782-1785, passim), dont «Discours sur le préjugé qui note d'infamie les parents des suppliciés. Par M. Sabathier», t. X, pp. 60-63); disciple de Montesquieu favorable à des peines adaptées aux mœurs, Pierre Pastoret (1790), II, pp. 121-131, 133-141), défend encore l'infamie (posthume pour les suicidés), mais graduée sur la nature du crime. 
pénal garde donc un reliquat de peines infamantes pour instrumentaliser la « dégradation civique »: exposition au carcan, bannissement, marque au fer chaud (T.P: travaux forcés; $F$ : faussaires), exécution du parricide la «tête couverte d'un voile noir $\gg^{20}$. Dans la République helvétique, si le code pénal de 1799 interdit de mentionner sur le registre des décès le «genre» de mort ignominieuse des «suppliciés », il maintient aussi la flétrissure pour tout condamné «convaincu d'une action infâme», exposé «pendant deux heures aux regards du peuple», avec «au dessus de sa tête, sur un écriteau [où], seront tracés en gros caractères, ses noms, sa profession, son domicile, le crime qu'il a commis et le jugement rendu contre lui »"1

\section{MUYART DE VOUGLANS: LÉGALISER L'INFAMIE}

Le Mémoire sur les peines infamantes, publié en 1780 par le pénaliste PierreFrançois Muyart de Vouglans dans ses Lois criminelles de France dans leur ordre naturel $l^{22}$, est certainement le seul traité rédigé en français durant l'Ancien Régime sur le problème de l'infamie pénale. Né en 1723 dans une famille de robe à Moirans près de Saint-Claude, mort le 14 mars 1791 à Paris, Muyart, ce «célèbre Jurisconsulte » selon Daniel Jousse (1704-1781) qui loue l' «ordre et [la] méthode » de ses traités ${ }^{23}$, a été avocat au Parlement de Paris dès 1741, puis Conseiller au Grand conseil du Roi, membre depuis avril 1771 du Parlement réformé du Chancelier Maupeou. Doctrinaire-praticien du droit pénal, il théorise une philosophie juridique d'inspiration providentialiste, finalisée dans une doctrine du droit public qui défend l'absolutisme de droit divin et le catholicisme comme religion d'État ${ }^{24}$.

Muyart, auteur de plusieurs traités de droit pénal écrits aux sources de la jurisprudence royale ${ }^{25}$, incrimine violemment les réformateurs du droit criminel qu'il

20 Code pénal de 1791 (art. 31-33), code pénal de 1810 (art. 13, largement 20-39), in Lascoumes, Poncella, Lenoël (1989, p. 358, 372); Code pénal pour le Bas-Valais (1794, XIII, i, p. 29), "Quiconque invitera et provoquera un autre à un duel ou cartel, de quel rang et condition qu'il puisse être, seron incontinent déclaré et réputé publiquement pour Infâme, et subira un bannissement de six ans »; ibid., (XXXV, iii, pp. 50 et L, i, p. 6)1: exposition, écriteau puis tourniquet d'infamie pour les voleurs étrangers; traction sur la claie du cadavre du suicidé par l'exécuteur de la haute-justice.

21 Bulletin des lois et décrets du corps législatif (1798), Loi du 4 mai 1799, Code pénal, Partie I, I, 2832,213 , pp. 546-547, 589.

22 Les Lois criminelles de France dans leur ordre naturel. Dédiées au Roi, Paris, Chez Merigot le jeune, Libraire, Quai des Augustins, au coin de la rue Pavée; Crapart, Libraire, rue d'Enfer, près de la Place Saint-Michel; Morin, Imprimeur-Libraire, rue Saint-Jacques, à la Vérité. MDCC.LXXX. [1780], avec approbation et privilège du Roi, xliij, 884 p., [in fol.], pp. 832-838; idem, Paris, Neufchâtel, 1781, Société Typographique, 2 vol. [in quarto] (nouvelle édition augmentée des «Déclarations du Roi, du mois d'Août 1780, concernant l'Établissement de nouvelles prisons, et l'abolition de la Question préparatoire). Ce manifeste d'un providentialisme judiciaire hostile ঐ la «philosophie» des Lumières a été traduit en italien: Le leggi criminali nel loro ordine naturale, prima versione italiana, Milan, 1813,4 vol., cxx-160, 402, 384 et 450 p. (vol. III à VI de la « Raccolta dei classici criminalisti»). Merci à Mario Sbriccoli de m'avoir signalé cette traduction de Muyart selon le bel exemplaire de sa bibliothèque personnelle.

Traité de la justice criminelle de France, 1781, p. xliij, «Préface».

Besson (1837); Cordero (1981, pp. 421-425); idem (1985, pp. 54-64); Laingui (1964, pp. 179-277).

Outre les Lois criminelles dans leur ordre naturel, ouvrage qui applique au droit pénal le plan des lois ecclésiastiques de Louis d'Héricourt (1687-1752, Lois ecclésiastiques de France, mises dans leur ordre naturel, Paris, 1729) ainsi que la philosophie providentialiste et jusnaturaliste de 
accuse d'attiser le crime en prônant la douceur des peines. Légitimant encore la pénalisation des «crimes contre la religion » (notamment les «Hérésies de Luther et Calvin ») qu'un Montesquieu récuse, hostile à la "philosophie du temps» qui nie la révélation de la foi par les miracles ainsi que la "vérité de la Résurrection» du Christ, le pénaliste milite contre les Lumières par le biais d'une science juridicothéologique ${ }^{26}$. Il récuse toute pensée juridique laïcisante qui attaque l'autorité du droit positif fondé sur la tradition politique de l'absolutisme de droit divin et la jurisprudence royale. Puisque les lois positives traduisent un «ordre naturel» voulu par Dieu, il combat en 1766 la doctrine du contrat social d'inspiration rousseauiste, ainsi que l'abolitionnisme (question, peine capitale pour les crimes de droit commun) de Beccaria, puis dénonce en 1775 la «modération» pénale de Montesquieu dont le système pernicieux triompherait, selon Muyart, dans le réformisme du Parlement de Paris $^{27}$.

Les juristes réformateurs d'inspiration beccarienne estiment que la criminalité résulte de l'inégalité juridique de la société de l'Ancien Régime. Au contraire, pour Muyart, le mal du crime traduit le mal ontologique du pécheur (péché, mal, injustice, etc.). Seule une pénalité expiatoire, qui flétrit le corps et l'âme, réduira l'homo criminalis. Partisan de la peine capitale pour «exterminer le méchant, servir d'exemple et détourner les autres de mal faire, enfin purger la société et la préserver de la contagion», Muyart défend la sévérité des supplices. Ceux-ci, selon le principe de la «juste proportion» entre l'atrocité de l'homicide et la dureté de la peine, visent à reconstruire la perfection morale du pécheur, «rompu vif», pendu ou décapitée ${ }^{28}$. $\mathrm{A}$ la neutralisation s'ajoute alors la stigmatisation, comme mal moral et physique pour meurtrir l'individu dans la conscience de ses tourments: «Le supplice de Damiens, souligne Muyart, a duré deux heures, lui vivant ${ }^{29}$. Pour les réformateurs, a contrario, seule est licite la peine neutralisante, sans flétrissure corporelle. Réclamée par Montesquieu, Beccaria, Servan ou Brissot de Warville, appliquée par les magistrats éclairés qui déplorent que les «peines servant à l'exemple ne puissent aussi servir à la correction», selon le procureur général de Genève Jean-Robert Tronchin $(1761)^{30}$, la modération pénale, motivée au nom de la perfectibilité humaine, peut corriger et resocialiser l'homo criminalis. Or, bien que favorable au statu quo pénal qu'il défend contre les «philosophes», Muyart récuse partiellement la flétrissure dans son Mémoire sur les peines infamantes que nous allons lire ici.

Entre jus romanum (Digeste), droit coutumier de France, lois positives et jurisprudence royale, Muyart inscrit sa critique de l'infamie pénale dans le cadre d'une

Jean Domat (1625-1695, Les lois civiles dans leur ordre naturel, Paris, 1689), Muyart a laissé: Institutes au Droit criminel, 1757; Instruction Criminelle, 1762.

"Discours préliminaire sur l'Origine, l'Importance et la Division des Lois Criminelles », in Lois criminelles dans leur ordre naturel (1780, p. xxvij-xliij); herresies, ibid. (pp. 103-115); Motifs de ma foi en Jésus-Christ ou points fondamentaux de la Religion Chrétienne, discutés suivant les principes de l'Ordre judiciaire, ibid. (pp. 839-863).

27 Réfutation du Traité des délits et des peines (1765), publié in Les Lois criminelles dans leur ordre naturel (1780; pp. 811-831, dont les pp. $825-826$ contre Rousseau); cf. Beccaria (1965, pp. 425430); Lettre sur le système de l'auteur de L'Esprit des lois, touchant la Modération des Peines (1775), in Porret (1997).

28 Muyart de Vouglans (1780, pp. 39, 45, 54, 57-59).

29 Ibid. (p. 56, nous soulignons).

30 PC 10873, «Vol», «Conclusions » du procureur général ; sur l'utilitarisme des magistrats genevois, cf. Porret (1995, «Index général », pp. 535-555). 
réflexion jusnaturalisante, concernant le rôle préventif du droit de punir et la dimension expiatoire de la peine qu'impose la loi. Indispensable à l'ordre social, matrice de l'absolutisme de droit divin, parfaite en théorie car aspirant à la sécurité de l'État, des individus et des biens, la loi est corrompue par l'usage des tribunaux, notamment inférieurs, qui en négligent l'esprit. Même arbitraire, elle reste perfectible, aménageable, surtout lorsqu'elle «concerne l'imposition des peines ${ }^{31}$, harmonisées sur la nature du crime. Or, selon Muyart, les jugements qui oublient le «véritable point de correspondance [devant] se trouver entre la Peine et le Crime» altèrent l'idéal juridique de la proportion entre la «qualité du Crime» et la peine juste: l'infamie amplifie cette discordance. Pour Muyart, les effets sociaux de l'infamie nuisent en outre aux individus dans un État où le «point d'honneur», ce "principe» fondamental de la monarchie selon Montesquieu ${ }^{32}$, marque le «caractère de [toute] la Nation ».

La discussion sur l'infamie recoupe donc celle de la protection des justiciables: selon Muyart, un «des principaux objets de [la] Législation Criminelle [du] Royaume, doit tendre à déterminer [avec certitude] la manière dont on doit procéder dans l'imposition de ces sortes de Peines qui emportent l'Infamie ou la Flétrissure des Condamnés ». La critique de l'infamie mène, selon Muyart, à celle de l'arbitraire des juges (Parlements) dans la motivation et l'application des peines les plus sévères. Leur arbitraire doit donc être endigué: en effet, non seulement l'infamie flétrit le condamné, mais en outre elle frappe sa famille de ses retombées humiliantes. Contrevenant au principe de l'individualisation de la peine, l'infamie marginalise des sujets du roi qui auraient pu être utiles à la «société et à leur patrie».

De jure et de facto: héritée du droit romain, cette conséquence juridico-sociale de l'infamie s'estompe partiellement dans celui de la monarchie. Peine principale ou peine accessoire, elle naît toujours d'une condamnation judiciaire, même si son intensité dépend de celle de la sanction. À peine légère et correctrice, répond l'infamie partielle, soit la «simple diminution de l'estime des honnêtes gens, laquelle ne produit aucune incapacité dans la personne des condamnés». Au contraire, suite à un «crime atroce», lorsque, non prononcée par un tribunal militaire, la peine «considérable» (mort sauf la «décollation» des aristocrates, galères, bannissement perpétuel) se confirme en appel, l'infamie culmine alors dans la mort civile. En cas de jugement prononcé par contumace, celle-ci prend fin si le condamné fugitif se rend dans les cinq années suivant son procès. Évoquée onze fois par Muyart, privant le condamné de tous ses droits, la «mort civile, écrit l'avocat Pierre Richer en 1755, est une fiction, par laquelle on regarde celui qui l'a encourue comme mort naturellement, relativement au droit civil, auquel il ne participe en aucune façon. Or c'est une maxime certaine, en matière de fiction, qu'elle doit réellement imiter la vérité, et prendre tellement les apparences, que la fiction disparaisse. C'est pourquoi, comme on ne peut être mort naturellement pour un temps, de même, quand on est mort une fois civilement, on l'est pour toujours ${ }^{33}$. Légalisées par l'ordonnance de 1670 , mais en recul dès 1750 , les peines corporelles (fustigation jusqu'au sang,

31 Dorénavant, nous renvoyons au Mémoire sur les peines infamantes (publié ci-dessous) sans en mentionner la pagination.

32 Montesquieu (1748, III, vi, vii), «L'Honneur, c'est-à-dire le préjugé de chaque personne et de chaque condition [...] qui fait mouvoir toutes les parties du corps politique».

33

Richer (1755, p. 28). 
essorillement, langue coupée ou percée, poing coupé) n'emportent pas systématiquement, selon la jurisprudence royale, la mort civile, mais induisent seulement la «note d'infamie», née de la flétrissure physique.

Pour Muyart, les juges, notamment dans les juridictions inférieures (juges seigneuriaux) ou extraordinaires qui échappent à l'appel obligatoire (maréchaussée), abusent de l'infamie. D'abord, parce qu'ils oublient qu'elle est «perpétuelle», que ses effets marginalisent le condamné: flétri, un «Accusé [...] est tenu de s'expatrier pour cacher sa honte et son infamie». Ensuite, cet abus provient des carences de la loi (ordonnances royales) qui qualifie mal 1'infamie. Finalement - et surtout - l'excès dans l'application de l'infamie résulte de la routine judiciaire. Inspirés par une philosophie pénale répressive, sécuritaire et expiatoire, les juges négligent cette «maxime inviolable de Droit, qui veut que ce ne soit point tant la Peine, que la cause pour laquelle elle est infligée, qui produise l'Infamie». Même jugé en appel, comme l'exige l'ordonnance de 1670, un procès infamant pour un accusé risque la confirmation. Si celui-ci, incarcéré avant l'exécution de sa peine, peut demander la révision ou la cassation de son procès, voire recourt à la justice retenue du roi (recours au Prince), les résultats sont incertains: les tribunaux supérieurs motivent peu leurs décisions qui visent moins l'infamie elle-même que les «cas [généraux] résultant du Procès». Laissant une «impression perpétuelle sur la personne» (mutilations), humiliant d'une «manière ignominieuse » l'individu mis au pilori, l'infamie, pour Muyart, doit être légalisée pour en diminuer les effets.

Les «ravages affreux que produit l'[Infamie]» culminent lorsqu'elle résulte d'un jugement prononcé par contumace sans que l'accusé ait pu plaider sa cause. Coupable, il fuira les rigueurs de sa peine infamante, dont l'ordre d'exécution ressort du Tableau d'Effigie (publié à «son de trompe») qui le signale au public. Innocent, il ne peut recourir à l'autorité d'une cour supérieure sans purger sa contumace et reconnaître ainsi son infamie. Bilan public du jugement et creuset du déclassement social, l'effigie détruit la réputation du justiciable marqué de la note d'infamie. Si, d'ailleurs, le condamné innocent meurt sans s'être "représenté» devant ses juges, sa mémoire reste flétrie ad ceternam, même si ses parents peuvent la «purger», ce qui suppose un «crédit» social et une «fortune» importante pour engager la révision du procès.

Mieux qualifier le crime commis: telle est la condition, selon Muyart, pour limiter le recours à l'infamie et ses conséquences sociales. Le juge établira minutieusement les «circonstances» du crime en qualifiant avec certitude la préméditation, la récidive, la «bassesse morale», ou encore en cernant l'individualité de l'accusé, sa sensibilité à l'honneur ou au déshonneur, ses capacités à la réhabilitation.

Adversaire des réformateurs du droit pénal qui militent dès les années 1750 pour la modération et la certitude des peines correctrices, la fin de l'infamie et la légalisation d'une pénalité non expiatoire, Muyart condamne ainsi la flétrissure pénale. Récusant une pénalité trop marginalisante, il contribue à définir un nouvel horizon d'attentes en matière de rétribution pénale, comme le font aussi les procureurs généraux de Genève qui voient dans l'infamie une «école du crime » ${ }^{34}$. Pour Muyart, l'infamie corrompt l'esprit de la loi sans corriger l'homo criminalis. D'autre part, si l'infamie humilie définitivement celui qu'elle flétrit par la mort civile, elle contredit

34

Porret (1995 a). 
au principe universel de la pénalité : aucune peine, sauf la mort, ne saurait être éternelle. Socialement marginalisante, l'infamie est négative dans ses effets, car, dans le système pénal de l'Ancien Régime où l'individualité reste faible, elle retombe sur «toute la famille [du] Condamné [qui] se trouve enveloppée dans sa disgrâce, et partage son opprobre». En conséquence, la «société se trouve [...] privée d'une infinité de secours essentiels qu'elle aurait pu tirer de leurs services et de leurs talents». Pour «remédier» et «prévenir» les «inconvénients [de l'infamie] aussi fâcheux que contraire au bien de la justice», Muyart propose dix-huit principes juridiques qui veulent en limiter les effets.

\section{DIX-HUIT PRINCIPES POUR LIMITER L'INFAMIE}

Muyart veut que la législation royale détermine d'une «manière précise» les peines qui «doivent être réputées infamantes» (Principe 1 ) et celles qui en outre emportent exclusivement la mort civile (2). À ces exigences codificatrices de certitude pénale endiguant l'arbitraire des juges, Muyart ajoute l'obligation de «marquer» le temps où commence la mort civile après un jugement par contumace: immédiatement dès le prononcé de la sentence, ou après les cinq années durant lesquelles court la contumace (3). Pour limiter l'excès dans l'application de la flétrissure et mieux harmoniser la peine sur la nature du délit, Muyart souhaite que l'infamie ne sanctionne que des crimes «immoraux» (4) et non pas de «simples délits commis en fait de police» (6). À ce principe de restriction pénale, il ajoute celui de la motivation obligatoire: si la «cause est [jugée] infamante», le juge la motivera clairement dans son décret $(4,5)$. Attaché à la dignité des charges étatiques, solidaire des hiérarchies de l'Ancien Régime, Muyart récuse au passage l'infamie pour «les Ecclésiastiques, les Nobles, les Militaires, et généralement [pour] tous ceux qui exercent des offices publics». Incriminées, ces «personnes de qualités » échapperont à la juridiction d'un simple juge pour être déférées à la «Chambre du Conseil» du roi $(8)$. Plus largement, Muyart veut légaliser et limiter la «peine infamante »: il exige qu'elle soit motivée dans un «Décret» et un "Règlement à l'extraordinaire », à l'exception de celle prononcée par le Lieutenant de Police qui peut ordonner souverainement l'incarcération infamante dans une Maison de Force. Pour que la peine soit correctrice, l'infamie ne sera plus infligée à «perpétuité » et aggravera rarement les sanctions pécuniaires $(9,10)$. Pour limiter encore les effets sociaux de 1'infamie, Muyart voudrait que les cours supérieures transforment arbitrairement la peine de «bannissement à temps» en simple «abstention des lieux». Celle-ci, d'ailleurs, ne visera que des accusations de crimes graves pour lesquels l'accusé «reprocher[a] ses témoins, poser[a] ses faits justificatifs» $(11,12)$. Pour mieux endiguer encore l'infamic, Muyart propose non seulement que les cours supérieures admettent les «requêtes des Condamnés par Contumace» (13) sans qu'ils la purgent, mais encore que le travail des avocats soit légalisé: «il y aura près de chaque Parlement ou Tribunal en dernier ressort, un Avocat principalement destiné à la défense des Criminels, et auquel il sera pour cet effet donné communication par le greffier du procès criminel, et en même temps la liberté de conférer avec l'accusé» (14). Fouet, marque, mutilations, carcan: pour modérer la nature irréparable des «peines corporelles et afflictives qui laissent une impression durable», Muyart veut en différer le moment de leur application publique après la sentence définitive. Le condamné ou sa famille auront ainsi le temps de se pourvoir 
contre le jugement ou de recourir à la clémence du roi (15). Partisan de la peine capitale, Muyart exige pourtant que les juges, privés de preuves certaines pour la motiver, renoncent alors à prononcer des «peines afflictives ou infamantes » (16) contre des justiciables qui échappent de peu au gibet. Afin de réhabiliter socialement le condamné qui retrouvera droits et charges au terme de sa peine, Muyart conseille, finalement, que la prescription de trente ans (jugement par contumace) exempte la peine du condamné et éteigne sa flétrissure. En outre, les «lettres de grâce ou celles de commutation des peines» $(17,18)$ purgeront définitivement l'infamie.

Dans ses écrits polémiques contre les «philosophes» (Montesquieu, Beccaria), Muyart, au nom du droit positif et de la corporation des juristes professionnels, déniait à ceux-ci le droit de sonder et de critiquer les fondements du droit pénal de la monarchie, même lorsque les réformateurs en évoquent les archaïsmes ou les routines. Avec son Mémoire sur les peines infamantes, il intente pourtant le procès modéré de l'infamie pénale en suivant partiellement les réformateurs post-beccariens. Il souligne ainsi les pernicieuses conséquences juridiques et sociales de l'infamie: maintenue par la routine des juges qui placent l'expiation corporelle et morale de l'homo criminalis avant sa correction, l'infamie transforme celui-ci en paria social et humilie sa famille. À l'éternité de l'infamie qui culmine avec la mort civile, Muyart oppose la temporalité limitée d'une sanction individualisée. Ne visant plus que des crimes qualifiés d' «atroces» en raison de leur immoralité, l'infamie sera modérée par la loi. Fort du conservatisme d'un magistrat attaché à l'appareil de justice, Muyart sauvegarde l'essentiel du système pénal de la monarchie absolue: l'infamie est maintenue par une législation qui en limite l'application. De cette manière, Muyart récuse partiellement l'arbitraire des juges lorsqu'ils s'enferment dans la routine de l'infamie mal motivée, destructrice de l'intégrité morale et physique des condamnés soumis à l'opprobre social. Implicitement, Muyart adhère au mot d'ordre humaniste de Montesquieu: si elle veut les corriger, la justice ne doit «point mener les hommes par les voies extrêmes $»^{35}$. Pour que le mal honteux de l'infamie ne contamine plus la sanction pénale, qui alors marginalise au lieu de resocialiser, il importerait impérativement de corriger ce que Montesquieu nomme encore la «nature » humaine «qui a donné aux hommes la honte comme leur fléau, et [l'idée] que la plus grande partie de la peine soit l'infamie de la souffrirs ${ }^{36}$. Remarque lucide: en effet, certains réformateurs, inspirés pourtant par Beccaria, adhèrent encore à la vieille pédagogie de l'effroi inhérente à l'infamie. En 1770, dans son Discours sur la nécessité et les moyens de supprimer les peines capitales, l'avocat du roi à la Chambre des comptes de Besançon Louis Philipon de la Madeleine (1734-1818), voulant punir moralement les mères infanticides, propose de flétrir chacune d'elles par un tite d'infamie immonde: «pendant un certain nombre de jours on la promène[ra] au milieu de nos places, chargé de tout le poids de la malédiction publique, tenant étroitement embrassé le cadavre qu'elle a privé de la vie, la bouche collée sur ses lèvres livides, contrainte d'en respirer l'odeur infecte, forcée de repaitre ses regards du spectacle le plus affreux qu'on puisse offrir à une mère ${ }^{37}$.

35 Montesquieu (1748, VI, xii).

36 Ibid. (nous soulignons).

37 Cité selon Porret (1994, p. 58). 
Dans le cadre de l'affirmation lente de l'État de droit, il reviendra au système légal des peines issu du code pénal $(1791,1810)$, qui abolit les supplices infamants de l'Ancien Régime pour l'égalité sociale devant la loi, de tenter de renverser la conception millénaire de la peine infamante comme sanction morale pour la remplacer par la peine de réhabilitation comme sanction juridique. Hérité des Lumières, cet idéal de perfectibilité juridique est condamné à l'échec. Partisan du système pénal expiatoire de l'absolutisme, Muyart voulait pourtant légaliser l'infamie pour la modérer: or, dès le XIX ${ }^{e}$ siècle, l'histoire des institutions pénales montre que le traitement carcéral des délinquants s'aggravera arbitrairement de mille «peines obscures ${ }^{38}$. Au bout de la chaîne judiciaire, derrière les murailles des établissements pénitentiaires, elles ajoutent à la peine légale le mal de la sanction morale : la prison ou le bagne deviennent alors, pour longtemps, le conservatoire et l'institution reproductrice de l'infamie et de la stigmatisation sociale. Cette stigmatisation qui frappe le repris de justice que portraiture une culture du fait divers ${ }^{39}$, fort habile à en montrer la «nature perverse et incorrigible», donc insensible à une pénalité correctrice qui ne flétrit pas son individualité.

\section{PIERRE-FRANÇOIS MUYART DE VOUGLANS}

\section{MÉMOIRE SUR LES PEINES INFAMANTES ${ }^{40}$}

Les Lois Criminelles ont pour objet tout ce qui concerne l'Instruction et la Punition des Crimes ${ }^{41}$. L'on ne peut disconvenir que, de toutes les Nations policées, il n'en est aucune qui puisse se vanter d'avoir un corps de législation plus complet que le nôtre sur l'un et l'autre de ces points ${ }^{42}$. Mais il faut convenir en même temps, que, semblables à des eaux dont la pureté s'altère à mesure qu'elles s'éloignent de leur source, ces mêmes Lois, tout admirables qu'elles soient dans la Théorie, n'ont pas laissé que d'éprouver dans leur exécution (quoiqu'à la vérité d'une manière moins sensible) le sort commun à tous les ouvrages des hommes, par les changements, ampliations ${ }^{43}$ et modifications successives que l'expérience a obligé d'y apporter: 1'on veut parler surtout de la Partie qui concerne l'imposition des Peines, qui est sans contredit la plus importante, comme étant le terme où viennent aboutir toutes les Lois de ce genre ${ }^{44}$.

\footnotetext{
38 Petit (1990).

39 Monestier, Cheyronnaud (1982).

40 Je remercie Sophie Bouvet d'avoir transcrit le texte de Muyart.

41 Sur le contentieux, la jurisprudence et les termes juridiques évoqués par Muyart, cf. Ferrière (1768).

42 Modéré mais contre les «philosophes», le meilleur commentaire inventoriant la jurisprudence royale (droit pénal) reste celui de Daniel Jousse (1771).

43 Richelet $(1735, \mathrm{I}$, p. 96), «ampliation ou extension, augmentation».

$44 O . C, 1670$, protocole initial: «l'instruction criminelle [...] contient par la crainte des châtiments ceux qui ne sont pas retenus par la considération de leurs devoirs ». Commune jusqu'à la fin de 1'Ancien Régime à la jurisprudence européenne et aux doctrinaires de France ou d'ailleurs, cette philosophie de la prévention générale par la «terreur des châtiments » fait écho aux principes de déterrition déjà énoncés par le jus romanum, Digeste, 48, 19 (De Panis), 28, 15: "Ut et conspectu deterreantur alii ab isdern facinoribus./Par le spectacle de ce supplice [exposition du cadavre des voleurs], les autres hommes sont détournés de commettre le même crime».
} 
La Peine, pour être juste, doit être proportionnée à la qualité du Crime; c'est là sans contredit la première et principale règle que doivent se proposer les Législateurs et les Magistrats ${ }^{45}$. Mais ce contraste prodigieux que l'on remarque tous les jours entre les Lois et les Jugements, et le plus souvent entre les Jugements eux-mêmes, quoique rendus sur des accusations du même genre, ne fait que trop sentir combien il est difficile de saisir ce véritable point de correspondance qui doit se trouver entre la Peine et le Crime. Cette difficulté ne vient sans doute que de ce qu'on ne considère point assez la nature de la Peine et ses conséquences, relativement à la qualité des Accusés et aux motifs particuliers qui les ont fait agir, et surtout au caractère dominant de la Nation dans laquelle cette Peine doit s'exécuter ${ }^{46}$.

En effet, c'est ici le point capital que se sont proposés les plus sages Législateurs, pour rendre leurs Lois plus efficaces et plus salutaires. De là aussi cette différence remarquable entre les Lois de Sparte et d'Athènes, et entre les Lois Romaines et les nôtres, quoique nous ayons d'ailleurs retenu plusieurs usages de cette dernière Nation sur les matières Civiles, surtout dans les Provinces de ce Royaume que nous appelons Pays de Droit écritt ${ }^{4}$.

Le caractère dominant de notre Nation est, comme l'on sait, une extrême délicatesse sur le point d'honneur ${ }^{48}$ : délicatesse qui a pris vraisemblablement sa source dans cette maxime de notre Droit Français, qui ne souffre point d'esclavage dans ce Royaume, et qui veut qu'en naissant sujets du Roi, nous naissions tous libres et citoyens $^{49}$. D'où il faut conclure qu'un des principaux objets de notre Législation

45 Montesquieu (1748, VI, xvi), «Il est essentiel que les peines aient de l'harmonic entre elles ». L'idéal de la proportion « géométrique » entre la nature du crime, qualifié selon ses «circonstances » (temps, lieu, mode opératoire, auteur du crime, qualité de la personne offensée, etc.), et la sévérité de la peine remonte au moins au jus romanum; Digeste, 48, 19, (De Ponis), 5, 2: «Refert et in majoribus delictis, consulto aliquid admittitur, an casu. Et sanè in omnibus criminibus distinctio haec pœnam aut justam eligere debet, aut temperammtum admittere./ll y a une distinction à faire dans les grands délits, s'ils ont été cormmis à dessein ou par accident. Et même dans tous les crimes cette distinction détermine à appliquer ou la peine stricte de la loi, ou la modération de cette peine». Dès les années 1760 , au nom d'un utilitarisme humanitaire qui, entre Montesquieu et Voltaire, parie sur la correction de l'homo criminalis plutôt que sur son élimination, Cesare Beccaria (1738-1794) associe la proportion à la modération pour penser la réforme du régime pénal à l'aune d'un calcul rationnel du droit politique de punir (1965, VI, pp. 15-17).

46 Montesquieu (1748, VI, xv), «je crois que les peines tiennent à la nature du gouvernement ».

47 Au sud d'une frontière imaginaire allant de l'île d'Oléron jusqu'au nord de Genève (Nyon), le midi du royaume français, pays de droit écrit, conserve le régime du droit romain. Dans le nord, en pays coutumier, dont l'Angoumois, la Marche, l'Auvergne, la Bourgogne et la Franche-Comté (65 coutumes générales, 300 locales), où les coutumes sont rédigées dès 1454 sur ordre royal (ordonnance de Montil-lès-Tours), existent en outre des îlots de droit écrit aussi marqués par le jus romanum.

48 Sur l'«auguste tribunal » du point d'honneur établi avec l'édit de septembre 1651 contre les duels pour accomoder les parties, cf. Ferrière (1768, II, pp. 342-343), «Point d'honneur»: «[...] les Maréchaux de France sont juges du point d'honneur entre les Gentilhommes et entre ceux qui font profession des armes. [...] Cette attribution de Juridiction est principalement pour empêcher les duels, dont le point d'honneur entre les Gentilshommes est presque toujours la cause »; ainsi que Billacois, in Garnot (1996).

49 Contre les philosophes jusnaturalistes auxquels Rousseau se réfère en disant que l'homme «est né libre» (Du Contrat social, 1762, I, i-iv), Muryart pense la liberté individuelle en terme de soumission du «sujet» à l'ordre juridique de l'absolutisme. Si les caractères de l'ancienne servitude féodale ont progressivement disparu en France durant l'époque moderne, à l'exception d'un reliquat de mainmorte déclinant d'ailleurs au cours des XVII et XVIII siècles, l'esclavage subsiste dans les colonies des Antilles. Cf. Code noir ou Recueil d'édits, déclaration et arrêts concernant la Discipline et le Commerce des Esclaves Nègres des Îles Françaises de l'Amérique (60 articles), 1685. 
Criminelle dans ce Royaume, doit tendre à déterminer la manière dont on doit procéder dans l'imposition de ces sortes de Peines qui emportent l'Infamie ou la Flétrissure des Condamnés ${ }^{50}$.

En effet, quel objet plus important et plus digne tout à la fois de la Justice et de la Bonté d'un Souverain, le père de ses sujets, que celui de renfermer en de certaines bornes cette liberté dangereuse que se donnent les Juges de prononcer indifféremment ces sortes de Flétrissures, lesquelles ne frappent pas seulement sur la personne des condamnés, mais encore sur leur innocente famille, en éloignant ou retranchant d'un même coup, et de la société et de leur patrie, une foule de citoyens qui auraient pu leur rendre des services essentiels ? ${ }^{51}$.

Les Romains distinguaient, comme l'on sait, deux sortes d'Infamies, l'une de droit, l'autre de fait, ils appelaient ainsi la première, parce qu'elle était prononcée expressément par la Loi en de certains cas qui sont marqués sous le Titre du Digeste De his qui notantur Infamiâ: savoir, contre ceux qui faisaient les métiers de Bateleurs et de Comédiens, ou le commerce honteux d'impudicité publique... qui trompaient leurs associés ou leurs Pupilles... qui violaient des dépôts... ou pillaient des successions (etc) ${ }^{52}$.

Quant à l'Infamie de fait, elle avait lieu singulièrement à l'égard de ceux qui avaient reçu quelque censure ou réprimande du Juge ou de leur père, dans son Testament. Celle-ci n'étant point comme la première, prononcée disertement par la Loi, elle ne produisait d'autre effet que de laisser dans l'esprit des gens de bien une impression défavorable contre ceux qui l'avaient encourue, imminutio existimationis apud probos viros ${ }^{53}$; au lieu que l'Infamie de droit avait de plus l'effet de rendre incapables d'exercer aucun office public, et d'être admis en témoignage, tous ceux qui se trouvaient dans les cas marqués par la Loi.

À notre égard, nous ne reconnaissons d'Infamie proprement dite, que celle qui résulte d'une condamnation en Jugement ${ }^{54}$; c'est pour cela que nous la mettons au nombre des Peines, et que nous lui donnons plus ou moins d'étendue dans ses effets, suivant les différentes manières dont elle est prononcée. Tantôt elle se prononce expressément comme Peine principale, et alors elle est connue sous le nom de Blâme ${ }^{55}$; tantôt elle se prononce implicitement et comme accessoire à une autre

50 Perte de l'honneur et de la réputation, l'infamie de droit provient alors de la condamnation pour crime qualifié au bannissement, aux galères à temps, ainsi qu'à toute peine corporelle ou moralement flétrissante (question avec la réserve des preuves, exposition, fustigation, marque, amende honorable); cf. O.C., 1670, XXV, 13.

51 Jusqu'au code pénal de 1791, qui décriminalise le suicide (néologisme en français dès 1732), durant l'Ancien Régime la loi permet d'instruire le procès d'un cadavre ou la mémoire d'un suicidé, $O . C$., 1670, XXII, 1-5. Intenté via un curateur, ce procès aboutit à l'infamie post mortem: les «cadavres de ceux qui se sont homicidés eux-mêmes [sont] traînés sur une claie la face contre terre et ensuite pendus par les pieds» à la potence. L'infamie posthume recoupe la prévention générale: «détourner les Hommes d'une action aussi exécrable et aussi inhumaine que celle d'être l'auteur de sa propre destruction [et faire] passer jusqu'à la postérité [les] traces flétrissantes de l'opprobre dont ils se sont couverts", Muyart de Vouglans (1757, pp. 536-537). Sous un régime pénal de non-individualisation des peines, l'infamie du suicidé stigmatise sa famille, privée en outre de la jouissance de ses biens confisqués par l'État.

52 Digeste (1805), 3, 2 («De ceux qui sont notés d'infamie »), 1.

53 Une diminution de la réputation auprès des gens vertueux.

54 Cf. supra, note 11 .

55 Muyart de Vouglans (1780, p. 77), «Du Blâme»: «Réprimande qui se fait par le Juge, en Chambre du Conseil, à celui qui y est condamné [pour avoir] commis d'autres Crimes qui méritent une peine 
Peine principale, soit corporelle, soit afflictive, soit pécuniaire ${ }^{56}$. Au premier cas, elle a le même effet que l'Infamie de droit chez les Romains, c'est-à-dire, qu'elle rend celui contre lequel elle est prononcée, incapable de faire les fonctions de l'Office ou du Bénéfice dont il est revêtu, et de plus, d'être admis en témoignage. Mais, au dernier cas, elle a des effets différents suivant la qualité des Peines principales auxquelles elle est attachée. Si ces Peines sont légères et ne tendent simplement qu'à la Correction, à une Réparation d'honneur faite à l'Audience, ou à des Réparations civiles, et à des Défenses à récidiver (etc.), alors elles n'opèrent, comme l'Infamie de fait chez les Romains, qu'une simple diminution de l'estime des honnêtes gens, laquelle ne produit aucune incapacité dans la personne des condamnés.

Mais si au contraire ces Peines sont considérables, il faut encore distinguer où ces peines vont, jusqu'à la Mort, aux Galères et au Bannissement perpétuel ${ }^{57}$. Dans tous ces cas, l'Infamie qui en résulte est connue sous le nom de mort civile ${ }^{58}$, dont l'effet est beaucoup plus étendu que celui de l' Infamie proprement dite, en ce qu'elle rend le Condamné, non seulement incapable de faire les fonctions des Offices publics, mais qu'elle le prive même du titre de ces Offices; qu'elle le rend incapable de tous contrats civils, soit à titre gratuit, soit à titre onéreux, d'ester en Jugement, de tester, de succéder; qu'elle donne ouverture aux successions, aux substitutions, usufruit, douaire, droits féodaux, dissolutions de société; et qu'en un mot, elle emporte la Confiscation de tous les biens de ce même Condamné.

Il faut néanmoins remarquer: $1^{\circ}$. Quant aux peines de Mort, que celle de la Décollation ou de la Tête tranchée, ainsi que celles prononcées dans les Tribunaux Militaires, ne produisent aucune sorte d'Infamie dans nos Usages ${ }^{59} .2^{\circ}$. Qu'à l'égard de celles des Galères et du Bannissement perpétuel, ces Peines emportent toujours 1'Infamie, avec cette différence seulement, que si elles sont portées par un Jugement de Contumace, le Condamné peut faire cesser cette Infamie, et en même temps la Mort civile, par sa représentation dans les cinq années, à compter du jour de l'exé-

Infamante, moindre néanmoins que celle du Bannissement à temps »; le blâme est prononcé contre l'accusé, encadré par deux huissiers de justice, qui est agenouillé « dans le Barreau [...] tête nue, sans épée, ni canne».

56 Ibid. (pp. 59-67, 68-74, 81-88); les «peines corporelles», sans menacer la vie «tendent à l' effusion du sang, ou à l'amputation de quelques membres; ou même qui causent de la douleur au corps par l'état de gêne et de contraintes où elles mettent» (question, galères, fouet, flétrissure avec un fer chaud, mutilations diverses, suspension sous les aisselles, exposition au carcan ou pilori, amende honorable, etc.). Au contraire, afflictives sont les peines qui, comme le bannissement, la réclusion dans une maison de force ou la prison perpétuelle, ne visent à gêner la «liberté, sans causer aucune douleur sensible au corps de celui qui les subit». Finalement, les peines pécuniaires sont celles qui «peuvent cesser avec de l'argent», certaines emportent la note d'infamie de droit: confiscation, amende prononcée en matière criminelle.

O.C., 1670, XXV, 13.

58 Cf. Richer (1755), passim.

59 Muyart de Vouglans (1780, p. 58), «De la Décollation. Nous plaçons cette Peine dans le dernier ordre des peines de Mort, non seulement parce qu' elle paraît la moins rigoureuse, mais parce qu'elle n'emporte point parmi nous la note d'infamie, comme les précédentes [feu vif, roue, potence]. C'est pour cela qu'elle est principalement réservée pour les personnes Nobles» (nous soulignons). Décapitation contre supplice: ce privilège nobiliaire en matière de peine capitale non infamante sera généralisé à tous les justiciables par le Code pénal $(1791,1810)$ au nom de l'égalité sociale devant la loi : "Tout condamné à mort aura la tête tranchêe». 
cution du Jugement de Contumace ${ }^{60} .3^{\circ}$. Qu'enfin, comme $1^{\prime}$ Infamie et la Mort civile que produisent ces Peines dont nous venons de parler, est fondée principalement sur ce qu'elles privent pour toujours le Condamné de la liberté naturelle, sans laquelle on ne peut jouir des Droits de Cité; l'on doit aussi comprendre par la même raison, dans le nombre des Peines qui emportent la Mort civile, la Détention perpétuelle dans une Maison de Force, lorsqu'elle est prononcée dans les Tribunaux ordinaires. C'est aussi ce qui résulte de la Déclaration du 4 Mars 1724, qui met cette peine au rang de celles des Galères perpétuelles ${ }^{61}$.

Mais il n'en est pas de même à l'égard des autres Peines corporelles, afflictives et pécuniaires qui sont usitées parmi nous, telles que le Fouet et la Marque avec un fer chaud, la Langue coupée ou percée, le Poing coupé, le Carcan, le Pilori, les Galères et le Bannissement à temps, la Détention à temps dans une Maison de force ou un Hôpital, le plus Amplement informé indéfini, l'Amende honorable, l'Amende simple en matière Criminelle, lorsqu'elle est prononcée par Arrêt, l'Aumône en matière Civile, lorsqu'elle est pareillement prononcée par Arrêt: l'on sait que ces dernières Peines n'emportent point la Mort civile, mais seulement l'Infamie dans nos Usages ${ }^{62}$. Quand nous disons, dans nos Usages, nous voulons parler seulement de la Jurisprudence générale de nos Tribunaux : car, à la réserve de l'Amende dont il est parlé dans l'art. 7 du Tit. 25 de l'Ordonnance de 1670, nous ne voyons nulle part dans cette ordonnance, ni dans les précédentes, qu'il y soit fait mention des Peines auxquelles ces Lois ont entendu attacher la note d'Infamie ${ }^{63}$. L'on ne voit pas même qu'il y soit parlé des Peines afflictives, autrement que pour marquer les cas où il y a lieu de décréter de Prise de corps, ou de régler le Procès à l'extraordinaire, ou de faire subir le dernier Interrogatoire à l'Accusé, ou enfin d'introduire l'Appel de plein droit dans les Cours.

60 Ferrière (1768, I, pp. 439-443), une sentence par contumace est «rendue par défaut» contre un condamné absent ou fugitif qui, proclamé à «son de trompe», a été assigné à comparaître dans la quinzaine devant les tribunaux et dont le logis peut être perquisitionné, puis les biens saisis au profit du roi et des pauvres. Motivée dans un décret de "prise de corps", dont la force d'application dure cinq ans, elle implique l'exécution de la peine prononcée lorsque le condamné est repris (purger sa contumace). Dès 1'Ordonnance de 1670 (XVII, «Des Défauts et Contumaces», 1-32), les «seules condamnations de mort naturelle [sont] exécutées $»$ par l'effigie. Les autres peines infamantes prononcées par contumace (galères, amende honorable, bannissement perpétuel, flétrissure et fouet), sont exécutées au moyen d'un tableau écrit qui est attaché sur le pilori en place publique. En ce qui concerne les peines non corporelles et non infamantes, le jugement par contumace est porté dans un registre dont une copie est baillée au domicile du condamné.

61 Déclaration du Roi du 4 mars 1724 concernant la punition des Voleurs, art. I: «Ceux et celles qui se trouveront à l'avenir convaincus de vols et de larcins faits dans les Églises, ne pourront être punis de moindre peine, que, savoir les hommes, de celles des Galères à temps ou à perpétuité; et les femmes flétries d'une marque en forme de lettre $V$ et enfermées à temps ou pour leur vie dans la Maison de force [...]»; cité selon du Rousseaud de la Combe (1762, pp. cxvi-cxvii).

62 Muyart synthétise ici ce qu'il a développé dans les Lois criminelles de France, «Des Différentes espèces de Peines usitées dans ce Royaume», pp. 53-88. La pratique pénale montre qu'au XVIII siècle les mutilations se raréfient, même si la marque subsiste pour identifier les récidivistes. Dans un contexte de réaction «anti-philosophique» soutenue par le parlement de Paris, l'écartèlement en place de Grève du régicide Damiens (1757) ou le supplice du «blasphémateur » Chevalier de la Barre (1766), roué publiquement à Abbeville et dont le cadavre est incinéré avec un exemplaire du Dictionnaire philosophique portatif de Voltaire, sont exceptionnels.

$63 \quad O . C ., 1670, \mathrm{XXV}, 7$ : «L'amende payée par provision [...], ne portera aucune note d'infamie». L'Ordonnance, on le sait, n'est pas un code des délits et des peines, mais un précis d'instruction criminelle; seul l'article 13 du titre XXV (Des Sentences, Jugements et Arrêts) énonce la hiérarchie des peines (de la mort naturelle au bannissement à temps). 
C'est aussi de ce défaut de mention expresse que les Juges se sont fait sans doute un prétexte pour se croire autorisés à prononcer arbitrairement ${ }^{64}$ ces Peines afflictives et infamantes, sans faire attention à cette maxime inviolable de Droit, qui veut que ce ne soit point tant la Peine, que la cause pour laquelle elle est infligée, qui produise l'Infamie, sans distinguer aussi les Crimes commis par imprudence et dans un premier mouvement, de ceux qui l'ont été avec Préméditation, par Dol, Bassesse ou Trahison, sans distinguer non plus, parmi les Accusés, ceux dont le rang ou la naissance doivent leur rendre l'honneur plus recommandable et plus précieux que la vie même, et surtout sans faire cette réflexion essentielle, que la tache que produit l'Infamie est perpétuelle, et qu'elle subsiste même encore après la cessation de la Peine à laquelle elle est attachée, comme il arrive en fait de Galères ou de Bannissement à temps.

À la vérité, si les Jugements qui prononcent ces Peines sont rendus par de premiers Juges, ils peuvent être réformés par les Juges supérieurs ${ }^{65}$; mais dans ce cas-là même, combien n'y a-t-il pas de Jugements qui, quoique rendus en première Instance, ne sont point susceptibles de la voie de 1'Appel, tels que ceux rendus par les Prévôts des Maréchaux ${ }^{66}$, et par les Commissaires du Conseil ${ }^{67}$, ou bien lorsque les condamnations portées par les Sentences des premiers Juges n'excèdent point celles du Bannissement à temps, du Blâme et autres Peines simplement infamantes

64 Avant la légalité des délits et des peines, l'arbitraire du juge, attisé par son intime conviction, reposait sur sa capacité à qualifier un crime selon un faisceau de circonstances aggravantes ou atténuantes, mais aussi en suivant la jurisprudence et les «lois du Royaume ». Hérité du jus romanum (loi Hodié), l'arbitraire est un élément constitutif du droit pénal traditionnel: son sens est positif jusqu'aux années 1760 (arbitrage, médiation), puis devient péjoratif en raison de son utilisation politique (tyrannie, despotisme) dans le cadre du procès croissant intenté aux institutions de l'Ancien Régime, qu'elles soient absolutistes comme en France, ou "aristo-démocratiques" comme dans la République de Genève. Voir Schnapper (1973 et 1974); Porret (1995 a).

65 Établi dès 1624 pour les affaires de sorcellerie, l'appel de droit obligatoire vers le Parlement de Paris s'élargit à toutes les justices du ressort. Cette influence modératrice des parlements sur les justices locales culmine au cours du XVIII ${ }^{e}$ siècle, selon ce que légalise l'Ordonnance de 1670 (XXVI, 6): «Si la sentence rendue par le juge des lieux porte condamnation de peine corporelle, de galères, de bannissement à perpétuité, ou d'amende honorable, soit qu'il y en ait appel ou non, l'accusé et son procès seront envoyés ensemble, et sûrement en nos cours »; cf. Carbasse (1990, pp. 146-165).

66 Ferrière (1768, II), les « Prévots des maréchaux, sont des Juges d'épée, établis dans presque toutes les Provinces, pour faire le procès à tous vagabonds, gens sans aveu et sans domicile». Le contentieux de leur juridiction et leur larges compétences répressives dans le maintien de la sécurité des campagnes sont définis (respectivement) par l'article 12 du titre I et les 28 articles du titre II de l'Ordonnance de 1670. Sur la maréchaussée, tribunal de dernier ressort, cf. Castan (1976), ainsi que Dyonnet, in Porret (1997).

67 En matière de justice déléguée, les Commissaires du Conseil (recrutés notamment parmi les Conseillers d'État ou les Maîtres de requête), tiennent directement leur pouvoir du roi qu'ils «représentent » dans la poursuite en dernier ressort d'affaires criminelles exceptionnelles ou de délits qui menacent ou blessent immédiatement la souveraineté royale (instruction de l'Affaire des poisons en mars 1679 par la chambre de l'Arsenal qui poursuit 442 accusés). Selon Muyart de Vouglans (1780, p. 546: «Des Commissaires du Conseil en matière criminelle»), ces magistrats puissants peuvent former un tribunal limité dans le temps ou «fixe et perpétuel» (Chambre ardente) dans lequel ils «sont préposés pour juger en Dernier Ressort les Contrebandiers et Faux-Sauniers qui commettent des violences et des désordres dans les Provinces de leurs districts». Valence, Reims et Saumur sont" les villes où siègent ces cours suprêmes, «remèdes extraordinaires » utilisés par le roi pour juger «définitivement et sans appel » les délinquants relevant de la justice prévôtale (ibid., pp. 547-548, Lettres-patentes, portant établissement d'une Commission à Reims, pour juger les Contrebandiers, 22 novembre 1765 ). 
auxquelles l'Accusé a la liberté d'acquiescer suivant l'Ordonnance! Dans tous ces cas, le premier Jugement étant passé en force de chose jugée, devient un monument perpétuel d'opprobre pour cet Accusé, qui est tenu de s'expatrier pour cacher sa honte et son infamie. Cependant, ne peut-il pas arriver que ce premier Jugement soit rempli de nullité et d'irrégularités que cet Accusé n'a point été en état de relever, et qui ont pu échapper à la connaissance des Juges même qui ont procédé à la visite de son Procès, soit faute d'expérience suffisante en cette matière, soit pour s'en être rapporté trop légèrement au Juge de l'Instruction qui les a choisis? L'on veut parler singulièrement ici des Juges Seigneuriaux ${ }^{68}$.

Si au contraire l'affaire est portée dans les Cours supérieures par la voie de 1'Appel ${ }^{69}$ : que d'inconvénients dangereux cet accusé n'a-t-il pas encore à appréhender! Comment peut-il être en état de se bien défendre sur cet Appel, n'ayant aucune communication des charges et informations sur lesquelles il a été jugé? Il a bien pu, à la vérité, en avoir quelque connaissance par les Interrogatoires et les Confrontations; mais le trouble dont il était agité pour lors, le défaut d'intelligence ou de mémoire, assez ordinaire pour la plupart, lui permettront-ils de pouvoir donner sur ce point à son Défenseur tous les éclaircissements dont il pourrait avoir besoin ${ }^{70}$ ? Et combien peu s'en trouve-t-il d'ailleurs qui soient en état de se procurer ce Défenseur? On le Juge enfin: et si par l'Arrêt qui intervient, le premier Jugement est confirmé, le voilà dès lors (si ce Jugement prononce des Peines qui emportent la Mort civile) retranché absolument de la société; le voilà privé de tous ses Offices et Bénéfices; le voilà enfin dépouillé de tous ses biens, par la Confiscation qui en est une suite.

Il lui reste, à la vérité, une dernière Ressource contre cet Arrêt; c'est celle du recours au Prince, soit par la voie de la révision ou de la cassation, soit par celle des Lettres de Grâce ${ }^{71}$. Mais à combien d'inconvénients cette ressource n'est-elle point

68 Si la nuit du 4 août 1789 contribue à l'abolition générale des justices seigneuriales et municipales du royaume («justices subalternes») réclamée par la majorité des cahiers de doléance, la justice seigneuriale (haute et basse), notamment exercée par les baillis, constitue une particularité du puzzle juridictionnel de l'Ancien Régime hérité du régime féodo-seigneurial établi dès le XIII siècle. Plus nombreuses dans l'Ouest que dans le Midi du royaume où le droit écrit limite l'arbitraire des juges seigneuriaux, les justices seigneuriales, dès l'Édit de Crémieux (1537), se soumettent progressivement à l' autorité juridique du roi, incapable de les faire disparaître, même s'il leur impose divers instruments institutionnels de modernité judiciaire: tribunal en lieu clos, procureur fiscal, greffier, prison, géôlier. Fidèle à l'esprit centralisateur de l'Ordonnance de 1670, Muyart de Vouglans (1780, pp. 510-513), estime que les justices seigneuriales «f[on]t partie des Juridictions ordinaires», car elles sont soumises aux «Lois du Royaume» dans le respect de leur privilèges.

$O . C ., 1670, \mathrm{XXVI}$, «Des Appellations », 1: «Toutes appellations de sentences préparatoires, interlocutoires et définitives, de quelque qualité qu'elles soient, seront directement portées en nos cours, chacune à son égard, dans les accusations pour crime qui méritent peine afflictive»; cf. supra note 26.

70 Instruction préparatoire et instruction définitive : l'Ordonnance de 1670 (VI, XIV, XV, XXV) exclut le droit à la défense de l'accusé qui, sans avocat, est donc seul sur sa sellette face à ses juges pour plaider sa cause et présenter des faits justificatifs (ibid., XXVIII). Riche et puissant, l'accusé peut alors être soutenu au moyen de factums rédigés par ses avocats.

7 Souverain absolu, le roi, au nom de sa justice retenue, peut alors intervenir dans les cours de justice sur toute affaire criminelle. Lettres de rémission (homicides involontaires), lettres d'abolition ou lettres de pardon: les instruments de la clémence et de la miséricorde royale sont nombreux, ils permettent d'atténuer la sévérité des tribunaux, née de l'arbitraire des juges ou des exigences coutumières. O.C., 1670, XVI, «Des Lettres d'abolition, rémission, pardon, pour ester à droit, rappel de ban ou de galères, commutation de peine, réhabilitation et révision de procès», pp. 1-28. 
encore sujette elle-même ! Outre la difficulté qu'il y a d'y parvenir par l'incertitude des motifs qui ont déterminé l'Arrêt, à cause de l'usage où sont les Tribunaux Supérieurs de ne point exprimer les chefs particuliers d'accusation qui ont donné lieu à leurs Jugements, et de se contenter de cette clause générale pour les cas résultants du Procès: Qui ne sait d'ailleurs que cette ressource devient le plus souvent inutile au Condamné, par la prompte exécution de ces Arrêts, qui doit se faire, aux termes de l'Ordonnance, le jour même de leur prononciation? Exécution irréparable, surtout lorsque ces condamnations tendent au dernier supplice ou à de certaines peines corporelles qui laissent une impression perpétuelle sur la personne, telle que la Mutilation des membres, le Fouet et la Marque, la Langue coupée ou percée; ou bien lorsque la Peine s'exécute publiquement, et d'une manière ignominieuse, comme le Carcan et le Pilori ${ }^{72}$. Que peut faire d'ailleurs ce condamné qui est dans les fers? Il n'a plus de secours à espérer que du côté de sa famille; et cette famille est-elle toujours elle-même en état de faire les frais et les poursuites nécessaires pour parvenir jusqu'aux pieds du Trône, et y faire entendre sa voix. Enfin, à supposer même qu'elle parvienne à l'obtention des Lettres de Grâce ${ }^{73}$, et que le Crime en soit susceptible, qui ne sait encore, que ces Lettres n'ont d'autres effets pour l'ordinaire, que d'exempter de la Peine, et qu'elles ne lèvent point de la note d'Infamie, suivant cette maxime vulgaire, Princeps quos absolvit notat? ${ }^{74}$

Mais ce qu'il y a de plus terrible encore dans les ravages affreux que produit cette Infamie, c'est lorsqu'elle provient de condamnations portées par des Jugements de Contumace ${ }^{75}$, et sans que l'Accusé ait été entendu. En effet, qui ne sait que la crainte des horreurs d'une Prison, et de succomber enfin sous le poids du crédit et de l'oppression, peut faire sur l'esprit de cet Accusé, quoique innocent, des impressions assez vives pour l'empêcher de satisfaire au décret réel qui a été lancé contre lui par le Juge seul de l'instruction, et sans qu'il en sache la véritable cause, ne lui étant point signifié, et n'y étant point fait mention pour l'ordinaire du titre d'accusation? On instruit, en conséquence, la Contumace; on le fait publier à son de troupe; on le condamne; on fait exécuter son Jugement, soit par Effigie, si la condamnation va au dernier Supplice, soit par un Tableau où se trouve inscrit le Jugement, si la condamnation est aux Galères ou au Bannissement perpétuel ${ }^{76}$. La

72 Muyart de Vouglans (1780, pp. 66-67), «Du Carcan et du Pilori». Utiles pour la « vindicte publique», les peines du carcan et du pilori «sont toujours accompagnées d'écriteaux: elles produisent les mêmes effets quant à l'infamie», bien qu'elles differrent dans leur exécution. La peine du carcan s'exécute par l'exposition du condamné qui, après avoir parcouru les rues de la cité en marchant derrière la charrette de l'Exécuteur de la haute-justice, est attaché (quelques heures ou quelques jours) par le cou à un «poteau placé en place publique». En ce qui concerne la peine du pilori, lequel est disposé sur les places marchandes des villes (par exemple: Halles de Paris), l'exposition du condamné, dont la tête et les bras sont passés à travers trois trous percés dans une planche, se fait dans un «petit bâtiment carré, muré jusqu'à la moitié de la hauteur du Patient ". Lorsqu'il est installé sur un pivot, le pilori est régulièrement tourné afin de mieux exposer celui qui est soumis au déshonneur public.

73 Cf. supra, note 32.

74 Que le prince n'absolve celui qui est flétri: libre vulgate du principe énoncé notamment au livre III, titre II, du Digeste (1805): «hodie notari puto, non retro notatur/le jugement ne donne point d'effet rétroactif à l'infamie».

75 Cf. supra, note 21.

76 O.C., 1670, XVII, 16; Ferrière (1768, 1, p. 618), «Effigie, est l'exécution d'un criminel condamné à mort par contumace, laquelle se fait par la suspension d'un tableau en une place publique, où est dépeint le criminel, et où est écrit le Jugement qui le condamne. [...] L'effet de l'exécution d'une Sentence de condamnation rendue par contumace, est d'empêcher que le crime se prescrive par vingt 
frayeur de cet Accusé ne faisant qu'augmenter par la rigueur du Supplice qu'il sait qu'on lui prépare, ne fait que l'affermir de plus en plus dans l'intention où il était d'abord de ne point paraître. Que fera-t-il alors? Cherchera-t-il un asile dans l'autorité des Cours Supérieures? Mais ce serait inutilement, puisque l'Ordonnance défend expressément à ces Cours de recevoir aucune Requête de la part des Accusés dont la Contumace a été instruite et jugée, à moins qu'ils ne soient en état ${ }^{77}$.

C'est ainsi que ce premier Jugement, qui n'est le plus souvent que l'ouvrage de trois Juges, ou plutôt du Juge seul de l'instruction qui choisit deux Gradués à son gré pour l'assister, aurait toute la force d'un Jugement en dernier Ressort ${ }^{78}$. C'est ainsi que le Contumax laisse écouler les cinq années que l'Ordonnance lui accorde, pour empêcher, par sa représentation, que les condamnations prononcées par ce Jugement soient réputées contradictoires, et ne vaillent comme si elles étaient ordonnées par Arrêt $t^{79}$.

C'est ainsi, en un mot, que la Mort civile (si ces condamnations sont à la Mort ou aux Galères, ou bien au Bannissement perpétuel) se trouve irrévocablement encourue $^{80}$. Le voilà dès lors absolument retranché de la société, et incapable de tous contrats civils: si c'est un chef de famille, voilà sa femme et ses enfants privés des secours particuliers qu'ils pouvaient attendre de lui; et s'il est fils de famille, ses père et mère sont pareillement frustrés de toutes les espérances qu'ils avaient fondées sur sa personne. Mais ce qu'il y a de plus fatal encore, c'est que, par un effet malheureux du préjugé national, et contre cette maxime du droit naturel qui veut que la Peine du Crime suive son auteur, Pana solos authores et delinquentes cernere debet $^{81}$, toute la famille de ce Condamné se trouve enveloppée dans sa disgrâce, et partage son opprobre; en sorte que s'il a des parents constitués dans des places ou des grades honorables, on les voit dès lors réduits à la triste nécessité d'y renoncer, pour ne point être exposés à des reproches et à des humiliations continuelles; et par cette retraite forcée, la société se trouve enfin privée d'une infinité de secours essentiels qu'elle aurait pu tirer de leurs services et de leurs talents.

Telles sont cependant les terribles conséquences que l'on voit tous les jours résulter d'un Décret ${ }^{82}$ lancé par un premier Juge, qui le plus souvent est lui-même,

ans. Ainsi, quand elle a été exécutée, il faut trente ans pour prescrire le crime; au lieu qu'il n'en aurait fallu que vingt, si l'on en fût demeure à la simple condamnation ». Cf. supra, note 21 .

77. O.C., 1670, XVI, 17: «L'obtention et la signification des lettres ne pourront empêcher l'exécution des décrets, ni l'instruction, jugement et exécution de la conturaace jusqu'à ce que l'accusé soit actuellement en état dans les prisons du juge, auquel l'adresse en aura été faite».

78 Les gradués: magistrats pourvus d'un grade obtenu dans une Université (baccalauréat, licence, doctorat en théologie, droit ou médecine). Les gradués en droit peuvent être mis au bénéfice d'une charge d'avocat ou de conseiller dans un parlement, voire fonctionner comme des juges suppléants: «[...] en fait de jugement [ils sont] des personnes qui ont pris des gradués de Baccalauréat et de Licence Droit civil, que les Juges qui ne sont pas en assez grand nombre pour rendre un Jugement, peuvent prendre pour rendre le nombre des Juges complets», Ferrière (1768, I, p. 758). O.C., 1670, $\mathrm{XXV}, 10$ : «Aux procès qui seront jugés à la charge de l'appel par les juges royaux, ou ceux des seigneurs, auxquels il y aura des conclusions à peine afflictive, assisteront au moins trois juges qui seront officiers, si tant il y en a dans le siège, ou gradués ».

79 Sur le jugement rendu par contumace, cf. supra, notes 31 et 37 . Le «jugement contradictoire» est rendu par le juge uniquement après qu'il ait entendu toutes les parties qui ont défendu leur cause et leurs intérêts.

80 Sur la mort civile, Richer (1755).

81 La peine doit frapper seulement les instigateurs et les délinquants.

82 Ferrière (1768), I, p. 481, «Décret ou Ordonnance que le Juge rende en connaissance de cause, concernant la procédure et l'instruction »; O.C., 1670, X, «Des Décrets, de leur exécution et des élargissements», notamment rendus sur «conclusions [des] procureurs», pp. 1-24. 
ou incompétent, ou récusable, ou dont le Jugement ne porte que sur des dépositions de quelques témoins reprochables ou corrompus. Il reste, à la vérité, à ce Condamné par Contumace, deux sortes de ressources contre son Jugement, savoir, celle du recours au Prince, et celle de la Prescription. Mais combien peu s'en trouve-t-il qui soient dans le cas de profiter de ces dernières ressources!

$1^{\circ}$. Quant à celle du recours au Prince, nous venons de voir à combien d'inconvénients elle était sujette; il y a même cela de particulier en fait de Contumace, et qui forme le plus grand obstacle à cette voie, c'est qu'on ne peut être admis à se pourvoir en cassation, ou révision des Jugements rendus en cette matière, qu'après s'être mis en état et constitué dans les Prisons. Il y a d'ailleurs cela de remarquable par rapport aux Lettres de Grâce en général, que comme elles ne s'obtiennent que sur le vu des charges et informations, et pour des cas qui ne sont point du nombre de ceux que l'Ordonnance a déclarés irrémissibles ${ }^{83}$, il peut arriver très souvent que l'on en soit frustré uniquement parce que ces charges contre l'Accusé seraient fondées sur des dépositions de témoins reprochables ou subornés, qui auraient aggravé les circonstances du Crime, de manière à empêcher qu'il ne soit susceptible de Lettres de Grâce.

$2^{\circ}$. À l'égard de la Prescription, outre qu'elle ne peut s'acquérir que par le laps de trente années, à compter du jour de l'exécution du Jugement de Contumace, et par conséquent qu'il doit se trouver peu d'Accusés qui soient dans le cas de pouvoir faire usage d'une pareille exception: l'on sait d'ailleurs que cette prescription n'a l'effet que d'éteindre la Peine du Crime, et non point de faire cesser la Mort civile que l'Accusé aurait encourue par le laps de cinq années depuis l'exécution de son Jugement. À la vérité, si le condamné venait à décéder avant les cinq années sans s'être représenté, il resterait encore à ses Parents la faculté que leur laisse l'Ordonnance de se faire admettre à purger sa mémoire ${ }^{84}$; mais combien peu en voiton recourir à cette voie, par l'impuissance où les met le défaut de crédit et de fortune, et surtout la privation des secours et éclaircissements particuliers qu'ils auraient pu tirer de l'Accusé lui-même pour sa défense !

C'est donc pour remédier et prévenir, autant qu'il est possible, des inconvénients aussi fâcheux que contraires au bien de la Justice, que l'on pense qu'il serait à propos de fixer par une nouvelle Loi la juste idée que l'on doit se former des Peines infamantes, et en même temps la manière dont on doit procéder à l'imposition de ces sortes de Peines.

Pour cela, il paraît qu'il faudrait:

$1^{\circ}$. Déterminer d'une manière précise quelles sont les Peines qui doivent être réputées infamantes.

83 Les crimes de sang et ceux commis contre la justice et/ou la souverainetê de l'État êchappent à la rémission royale; $O . C ., 1670$, p. 4 : «Ne seront données aucune lettre d'abolition pour les duels, ni pour les assassinats prémédités, tant aux principaux auteurs, qu'à ceux qui les auront assistés [...]; ni à ceux qui, à prix d'argent ou autrement, se louent ou s'engagent pour tuer, outrager, excéder ou recourrent des mains de la justice les prisonniers pour crimes; [...] ni [pour] machination ou attentat [...], pour crime de rapt commis par violence; ni à ceux qui auront excédé ou outragé aucuns de nos magistrats ou officiers huissiers, et sergents exerçant, faisant ou exécutant quelque acte de justice». 
$2^{\circ}$. Distinguer parmi ces Peines celles qui doivent emporter la Mort civile,

$3^{\circ}$. Marquer le temps où la Mort civile doit commencer à produire son effet en matière de Jugement par Contumace; si c'est dès l'instant même de l'exécution de ce Jugement, ou bien seulement après l'expiration des cinq années depuis cette exécution.

$4^{\circ}$. Ordonner qu'aucune Peine infamante ne pourra être prononcée que pour des causes qui seraient infamantes par elles-mêmes, comme pour Crimes commis par Dol, Bassesse ou Trahison et contre la Foi publique ${ }^{85}$. Qu'à cet effet tous Juges, même ceux des Cours Supérieures, dans les Procès qu'ils jugeront en première instance, seront tenus d'exprimer les causes de la condamnation qui sera par eux prononcée.

$5^{\circ}$. Que pareillement tous les Décrets de prise de corps, par quelques Juges qu'ils soient rendus, contiendront la cause pour laquelle ils sont rendus; et cela, tant pour qu'on puisse connaître si cette cause est infamante, que pour s'assurer de la compétence des Juges qui les auront rendus.

$6^{\circ}$. Qu' aucune Peine infamante ne pourra être prononcée pour de simples Délits commis en fait de Police, sinon dans les cas où ces sortes de Peines se trouvent portées expressément par les Lois rendues en cette matière ${ }^{86}$.

$7^{\circ}$. Qu'aucune Peine infamante ne pourra être prononcée contre les Ecclésiastiques, les Nobles, les Militaires, et généralement contre tous ceux qui exercent des Offices publics, que dans les cas où il y aurait lieu de prononcer des Peines corporelles et afflictives contre de simples Particuliers.

$8^{\circ}$. Qu'il ne pourra être prononcé aucun Décret ni Règlement à l'extraordinaire contre les Personnes des qualités mentionnées ci-dessus, par le Juge seul de l'Instruction; mais qu'il sera tenu d'en référer à la Chambre du Conseil, ou de prendre 1'avis de deux Gradués, comme pour les Jugements définitifs ${ }^{87}$.

$9^{\circ}$. Qu'aucune Peine infamante ne pourra être prononcée qu'ensuite d'un Décret et du Règlement à l'extraordinaire, à la réserve seulement de celle de la Détention dans une Maison de Force ou Hôpital, lorsqu'elle sera prononcée par

85 Muyart de Vouglans (1780, pp. 11, 171, 186, 341, 312); morales, les «circonstances 》 «atroces» qualifient lourdement ces délits «infâmes» dont le mode opératoire signale l'infamie de fait du délinquant: abus de la confiance de la communauté pour les délits contre la foi publique (vols de bornes, de gerbes de blé dans les champs, de bétail dans les pâturages, de bois de chauffage ou de charpente sur les chantiers, de fruits et arbres dans les jardins, etc.); trahison de la confiance d'un individu lors d'un empoisonnement volontaire et prémédité de ses aliments ; lâcheté, dol, «passions basses et perfides » (bassesse) en cas de viol ou d'homicides qualifiés par la préméditation, la vengeance ou la cruauté.

${ }^{86}$ Ibid. (pp. 362-474), «Des Délits contre la Police»: innombrables, jugés en petit criminel ou devant le Tribunal du Lieutenant de Police, urbains ou ruraux, religieux ou séculiers, les «délits de police» représentent l'ensemble des infractions à l'ordre public ou aux «Règlements particuliers faits pour la Police extérieure de l'État »: irrévérences dans les Églises ou les cimetières, inobservation des jours fériés, trouble dans l'ordre des processions, délits contre la police des mours, scandale aux spectacles ou aux bains publics, prostitution, charivaris, désordre dans les cabarets et les rues, jeux d'argent, mendicité et vagabondage, contrebande, faux-saunage, délits de librairie, délits au sujet du prix, de la qualité et du poids des vivres, des boissons et des médicaments, infractions forestières (braconnage, pêche, chasse, etc.). Sur la police parisienne durant le siècle des Lumières, cf. El Ghoul (1995).

87 Cf. supra, notes 28 et 39. 
Monsieur le Lieutenant-Général de Police, ainsi qu'il est autorisé par la Déclaration du 26 Juillet 1713, et qu'elle ne sera point prononcée à perpétuité ${ }^{88}$.

$10^{\circ}$. Que les Amendes et Aumônes qui seront prononcées par Arrêts, n'emporteront note d'infamie que lorsqu'il en sera fait mention expresse dans ces Arrêts.

$11^{\circ}$. Qu'il sera libre aux Cours Supérieures de convenir en simple Abstention des Lieux, la Peine du Bannissement à temps, dans les cas où elles jugeraient à propos de sauver l'infamie aux Condamnés.

$12^{\circ}$. Que la Peine d'Abstention des Lieux, ainsi que celle de l'Admonition ${ }^{89}$, ne pourront être prononcées en matière d'Accusation de Crimes qui sont de nature à mériter Peine afflictive ou infamante, qu'ensuite d'une Instruction extraordinaire qui mette l'Accusé en état de reprocher ses Témoins, et de poser ses faits justificatifs.

$13^{\circ}$. Qu'il sera laissé à la prudence des mêmes Cours d'admettre les Requêtes des Condamnés par Contumace, encore qu'ils ne seraient point en état. Qu'elles ne pourront même refuser de le faire, à l'égard de ceux de ces Condamnés qui n'auront été décrétés originairement que d'ajournement personnel, et dont le Décret aurait été converti en celui de prise de corps.

$14^{\circ}$. Qu'aussitôt après la Confrontation ${ }^{90}$, il sera libre à l'Accusé de demander un Conseil (de quoi il sera averti à la fin de ladite Confrontation, ainsi que du délai qui lui sera accordé à cet effet): auquel Conseil il sera permis de prendre communication au Greffe des Charges et Informations, pour qu'il puisse se mettre en état de relever les Moyens de Nullité, d'Incompétence, de Récusation, de Reproches des Témoins et autres Moyens de droit et faits justificatifs qui pourront tendre à la décharge de cet Accusé; et que même, pour faciliter d'autant plus l'exécution du présent article, il y aura près de chaque Parlement ou Tribunal en dernier ressort, un Avocat principalement destiné à la défense des Criminels, et auquel il sera pour cet effet donné communication par le Greffier du Procès Criminel, et en même temps la liberté de conférer avec l'Accusé ${ }^{91}$.

88 Déclaration du Roi, du 26 Juillet 1713. Concernant la correction des femmes et des Filles de mauvaise vie: «Voulons que sur ledit appel, soit que l'affaire ait été jugée sur le simple procès civil du Commissaire, ou sur le récit ou le vô des informations, les Parties procèdent en la Grande Chambre de ladite Cour, encore qu'il y ait eu un décret sur lesdites informations, et que la suite de la procédure ait obligé ledit Lieutenant General de Police à ordonner que lesdites femmes ou filles seront enfermées pour un temps dans la Maison de force de l'Hôpital Général; en cas de Maquerellage, prostitution publique et autres, où il échoira peine afflictive, ou infamante, ledit Lieutenant General de Police sera tenu d'instruire le procès aux Accusés ou Accusées, par récollement ou confrontation »; cité selon Rousseaud de la Combe (1762, pp. cxj-cxji).

89 Muyart de Vouglans $(1780$, p. 80): 1 ' « Abstention des lieux » éloigne un individu (notamment aristocrate) d'une ville ou du thêâtre de ses méfaits en lui épargnant l' «infamie attachée à la Peine du Bannissement, dont elle tient lieu »; censure morale infligée au terme d'un jugement sur le parquet du tribunal, l' «Admonition » est une réprimande du juge à un délinquant primaire: celui-ci Evite l'infamie de l'amende honorable.

90 O.C., 1670, XV, «Des Récolements et Confrontations des témoins», 1-24; «Les confrontations seront écrites dans un cahier séparé, et chacune en particulier paraphée et signée du juge dans toutes les pages, par l'accusé et par le témoin, s'ils savent ou veulent signer, sinon sera fait mention de la cause de leur refus $\gg(13)$.

91 Cf. supra, note 31. En plaidant ici pour la légalisation du droit à la défense des prévenus, Muyart, partisan de la sévérité pénale contre la modération coupable des «philosophes » et des réformateurs beccariens, exprime une exigence de modernit judiciaire que formuleront, radicalement, les cahiers 
$15^{\circ}$. Que tous Arrêts et Jugements en dernier ressort portant condamnation à Mort ou autres Peines corporelles et afflictives qui laissent une impression durable [et] qui s'exécute[nt] publiquement, telles que le Fouet, la Marque, la Langue percée ou coupée, le Carcan et le Pilori, ne pourront être exécutés qu'après un certain délai, qui sera réglé suivant la distance des lieux; de manière que le condamné ou sa famille puisse avoir le temps nécessaire pour se pourvoir contre ces mêmes Arrêts et Jugements par les voies de droit, ou recourir à la clémence du Prince.

$16^{\circ}$. Que dans les Accusations de Crimes qui mériteront de leur nature la Peine de Mort, suivant les Lois et les Ordonnances ${ }^{\$ 2}$, les Juges, même ceux des Cours supérieures, ne pourront, lorsqu'ils ne trouveront pas la preuve suffisante pour passer à cette condamnation, prononcer des Peines afflictives ou infamantes, mais seulement prononcer par hors de Cour; ou plus amplement informé ${ }^{93}$ suivant l'exigence des cas.

$17^{\circ}$. Que la prescription de trente années, en fait de Contumace ${ }^{94}$, aura l'effet, non seulement d'exempter de la Peine le Condamné dont le Jugement aura été exécuté par Contumace, mais encore de faire cesser la Mort civile, à compter du jour de l'expiration des trente années; en sorte qu'il n'y aura que les seules Condamnations aux frais et dépens de Contumace qui pourront subsister.

$18^{\circ}$. Enfin, que les Lettres de Grâce, même celles de Commutation des Peines, auront l'effet de purger toute note d'infamie ${ }^{95}$, lorsqu'il y en sera fait mention expresse; de manière que ceux qui les auront obtenues, pourront, non seulement rentrer dans l'exercice des Offices ou Bénéfices dont ils auront été dépouillés, mais encore en acquérir de nouveaux.

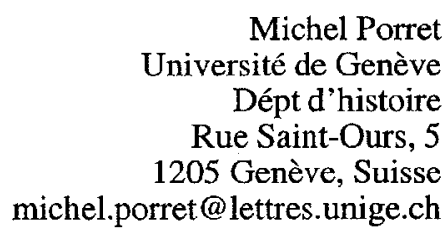

de doléances de 1789 , avant que le Code d'instruction criminelle de 1808 institutionnalise cet usage inhérent à 1 'État de droit. La doctrine conçoit pourtant le droit de défense, mal mis en pratique dans les Parlements de France (Carbasse, 1990), mais légalisée dans la République de Genève dès 1738 (Briegel, 1998).

Muyart de Vouglans (1780, pp. 53-59, 171-206, 289-291, 294-295): toujours motivée au nom de la prévention générale («exterminer les méchants, servir d'exemple et détourner les autres du mal faire»), la peine capitale, décollation pour les nobles et pendaison pour les rôturiers, sanctionne les crimes de lèse-majesté, les homicides «atroces» (empoisonnement, meurtres, assassinats, etc.) ou les vols qualifiés par la violence armée, la nuit, l'effraction ou l'abus de confiance («vol domestique $»)$.

Ibid., (pp. 78-79): à temps ou indéfinie, la sentence du plus amplement informé libère l'accusé tout en le laissant dans le «péril continuel » d'être repris et condamné à mort, puisque cette mesure d'infamie, particulièrement arbitraire lorsqu'elle est indéfinie, vise surtout les crimes capitaux. 


\section{RÉFÉRENCES}

\section{A. Sources}

Aristote, La Politique, Paris, Vrin, 1977 (introd. et notes par J. Tricot).

Beccaria C, Dei deliti e delle pene. Con una raccolta di lettere e documenti relativi alla nascita dell'opera e alla sua fortuna nell'Europa del Settecento (éd. par Franco Venturi), Turin, Einaudi, 1965.

Beccaria C., Des Délits et des peines (en italien, Livourne, 1764), Genève, 1965, introd. et notes par Franco Venturi).

Brissot De Warville, J.-P., Bibliothèque philosophique du législateur, du politique, du jurisconsulte [...], Berlin et Paris (10 vol.), 1782-1785.

Bruneau, A. Observations et maximes sur les matières criminelles [...], Paris, 1716.

Bulletin des Lois et décrets du Corps législatif avec les Arrêtés et Proclamations du Directoire exécutif de la République helvétique, $\mathrm{II}^{\mathrm{e}}$ cahier, Lausanne, 1798.

Code pénal (1791); Code pénal (1810), in Lascoumes, P., Poncela, P. Lenoël, P., Eds Au nom de l'ordre. Une histoire politique du code pénal, Paris, Hachette, 1989.

Code pénal pour le Bas-Valais, Sion, 1794.

Les cinquante livres du Digeste ou des Pandectes de l'Empereur Justinien (traduction par Hulot), Metz-Paris, I, 1805.

Encyclopédie Méthodique, Jurisprudence, Paris-Liège, 10 vol., 1782-1791.

Essai sur la politique et la législation des Romains (traduit de l'italien, Pise, 1772), Paris, An III.

Ferrière, C.-J. de, Dictionnaire de droit et de pratique contenant l'explication des termes de droit, d'ordonnance, de coutumes et de pratique. Avec les juridictions de France (1740), nouvelle édition, Paris, 1768 ( 2 vol.).

Isambert, F. (et al.), Recueil général des anciennes lois françaises depuis l'an 420 jusqu'à la Révolution de 1789, Paris (30 vol.), 1821-1833, t. XVIII.

Jeanclos, Y, La législation pénale de la France du XVI au XIX siècle, Paris, P.U.F., 1996.

Jousse, D., Nouveau commentaire sur l'Ordonnance criminelle du mois d'Aô̂t 1670. Avec un abrégé de la Justice Criminelle, Paris, 1763, puis 1777.

Jousse, D., Traité de la justice criminelle de France [...], Paris, 4 vol., 1771.

Montesquieu, De l'Esprit des lois (1748), Paris, 1961, Garnier (éd. par Gonzague Truc).

Muyart de Vouglans, P.-F. de, Institutes au Droit criminel ou Principes généraux sur ces matières, suivant le droit civil, canonique et la jurisprudence du Royaume, avec un Traité particulier des Crimes, Paris, 1757.

Muyart de Vouglans, P.-F. de, Instruction Criminelle suivant les Lois et Ordonnances du Royaume, pour servir de suite aux Institutes au Droit criminel, et au Traité des Crimes, Paris, 1762.

Muyart de Vouglans, P.-F. de, Réfutation du Traité des délits et des peines, Paris, 1765.

Muyart de Vouglans, P.-F. de, Lettre sur le système de l'auteur de L'Esprit des lois, touchant la Modération des Peines (1775), in Porret, M., à la suite de: «Les «lois doivent tendre à la rigueur plutôt qu'à l'indulgence », Muyart de Vouglans versus Montesquieu», Revue Montesquieu, 1997, I, pp. 65-95.

Muyart de Vouglans, P.-F de, Les Lois criminelles de France dans leur ordre naturel. Dédiées au Roi, Paris, 1780.

Muyart de Vouglans, P.-F. de, Les Lois criminelles de France dans leur ordre naturel, Neuchâtel, 1781. 
Muyart de Vouglans, P.-F. de, Le leggi criminali nel loro ordine naturale (prima versione italiana). Dedicata al Sig. Conte Antonio Strigelli, Commendatore dell'ordine della Corona di Ferro, Consigliere e Segretario di Stato [...], Milano, dalla Tipografia Buccinelli, 1813, 4 vol.

Pastoret, P., Des lois pénales, Paris, 1790.

Platon, Euvres complètes (Les lois, La République), Paris, Gallimard (Bib. de la Pléiade), 1950 (trad. nouvelle et notes par Léon Robin).

Richelet, P., Dictionnaire de la langue française ancienne et moderne, Bâle, 1735 (nouvelle édition).

Richer, $\mathrm{P}$., Traité de la mort civile, tant celle qui résulte des condamnations pour cause de crime, que celle qui résulte des vaux de religion, Paris, 1755.

Rousseaud de la Combe, G. de, Traité des matières criminelles suivant l'ordonnance du mois d'aô̂t 1670 et les Édits, Déclarations du Roi, Arrêts et Règlements intervenus jusqu'à présent, Paris, 1762.

Tripier, L. Les codes français collationnés sur les éditions officielles [...], Paris, 1850.

\section{B. Travaux}

Beattic, J., M., Crime and the Courts in England, 1660-1800, Princeton, New Jersey, Princeton U.P., 1986.

Besson, E., Un criminaliste franc-comtois au XVIII siècle, Muyart de Vouglans, Besançon, 1837.

Billacois, F., «Aux franges de l'infrajudiciaire: le tribunal du point d'honneur », in Garnot, B. (éd.), L'infrajudiciaire du Moyen Age à l'époque contemporaine, Dijon, EUD, Éditions universitaires de Dijon, 1996, pp. 251-256.

Briegel, F, La clémence du glaive: plaidoyer pour les criminels au siècle des Lumières à Genève, Genève, Université de Genève, Faculté des lettres, Département d'histoire générale, Mémoire en histoire moderne dirigé par Michel Porret, dactylogramme, février 1998.

Burford E.J., Shulman, S., Of Bridles and Burning. The Punishment of Women, Londres, Robert Hale, 1992.

Carbasse, J.-M., Introduction historique au droit pénal, Paris, P.U.F., 1990.

Castan, N., «La justice expéditive», Annales E.S.C., 1976, pp. 331-361.

Cordero, F., Riti e sapienza del diritto, Rome, Laterza, 1981.

Cordero, F., Criminalità, nascita dei sistemi penali, Rome, Laterza 1985.

Du Bois, Page, Torture and Truth, New York, Londres, Routledge, 1991.

Dyonet, N., «La maréchaussée et la culture judiciaire française au temps de Beccaria», in

Porret, M. (éd.), Beccaria et la culture juridique des Lumières, Genève, Droz, 1997, pp. 197-214.

El Ghoul, F., La police parisienne dans la seconde moitié du XVIII siècle (1760-1785), Tunis, 1995 ( 2 vol.).

Fasano, R., La torture judiciaire en droit romain, Neuchâtel, Université de Neuchâtel, 1997.

Galtier, P., L'Église et la rémission des péchés aux premiers siècles, Paris, 1932.

Gatrell, V. A. C., The Hanging Tree. Execution and the English People 1770-1868, Oxford, Oxford U.P., 1994.

Ginzburg, C., Le sabbat des sorcières, Paris, Gallimard, 1989.

Goglin, J.-L., Les Misérables dans l'Occident médiéval, Paris, Seuil, 1976.

Halm-Tisserant, M., Réalités et imaginaire des supplices en Grèce ancienne, Paris, Les Belles Lettres, 1998. 
Jouvenet, P., Étude sur le casier judiciaire. Origines, applications, réformes, état actuel, Paris, 1900.

Laingui, A., «Sentiments et opinions d'un jurisconsulte à la fin du XVIII ${ }^{e}$ siècle, PierreFrançois Muyart de Vouglans », Travaux juridiques de l'Université de Rennes, Rennes, 1964.

Masur, L.-P., Rites of Execution. Capital Punishment and the Transformation of American Culture, 1776-1865, New York, Oxford, 1989.

McLynn, F, Crime and Punishment in Eighteenth-Century England, Londres, Routledge, 1989.

Monestier, A., Cheyronnaud, J., Le fait divers. Catalogue de l'exposition tenue au Musée des arts et traditions populaires, Paris, Éditions de la Réunion des musées nationaux, 1982.

Page Du Bois, Torture and Truth, New York, London, 1991.

Panico, G., Il carnefice e la piazza. Crudeltà di Stato e violenza popolare a Napoli in età moderna, Napoli, Edizioni scientifiche italiane, 1985.

Petit, J.-G., Ces peines obscures. La prison pénale en France, 1780-1875, Paris, Fayard, 1990.

Pommeray, L., Etudes sur l'infamie en droit romain, Paris, 1937.

Porret, M., «Effrayer le crime par la terreur des châtiments»: la pédagogie de l'effroi chez quelques criminalistes du XVIII ${ }^{e}$ siècle», in Berchtold J., Porret M., (Eds.), La Peur au XVIII siècle, discours, représentations, pratiques, Genève, Droz, 1994, pp. 45-67.

Porret, M., Le crime et ses circonstances. De l'esprit de l'arbitraire au siècle des Lumières selon les réquisitoire des procureurs généraux de Genève, Genève, Droz, 1995 a.

Porret, M., «La biographie des scélérats ou les circonstances de la dangerosité criminelle durant l'Ancien Régime », Traverse, 1995 b, 2, Biographie-Biographies, pp. 55-65.

Porret, M., Les «lois doivent tendre à la rigueur plutôt qu'à l'indulgence». Muyart de Vouglans versus Montesquieu, suivi de P.F. Muyart de Vouglans, lettre sur le système de l'auteur de l'Esprit des lois touchant la modération des peines, Revue Montesquieu, 1997, 1 pp. 65-95.

Porret, M., «Signalement», «portrait parlé», cliché judiciaire: «le visage des scélérats», Images, 4, 1998 a (Centre de la photographie, Genève), Visage, pp. 34-41.

Porret, M., «Corps flétri-Corps soigné. L'attouchement du bourreau au XVIII siècle», in Porret M. (éd.), Le corps violenté, du geste à la parole, Genève, Droz, 1998 b, pp. 105135.

Puppi, L., Lo splendore dei supplizi. Liturgia delle esecuzioni capitali e iconografia del martirio nell'arte europea dal XII al XIX' secolo, Milan, Berenice, 1990.

Quanter, R., Die Schand und Ehrenstrafen in der deutschen Rechtspflege : eine kriminalstiche Studie, Dresde, 1901.

Robert, U., Les signes d'infamie au Moyen Age: Juifs, Sarrasins, Hérétiques, Lépreux, Cagots et Filles publiques, Paris, 1891.

Schnapper, B., «Les peines arbitraires du XIII ${ }^{e}$ au XVIII ${ }^{e}$ siècle (Doctrines savantes et usages français)», Revue d'Histoire du Droit, 1973, 41, pp. 237-277 et 1974, 42, pp. 81-112.

Spierenburg, P., The Spectacle of Suffering. Executions and the Evolution of Repression: from a Preindustrial Metropolis to the European Experience, Cambridge, C.U.P., 1984.

Zaremska, H., Les bannis au Moyen-Age, Paris, Aubier, 1996. 